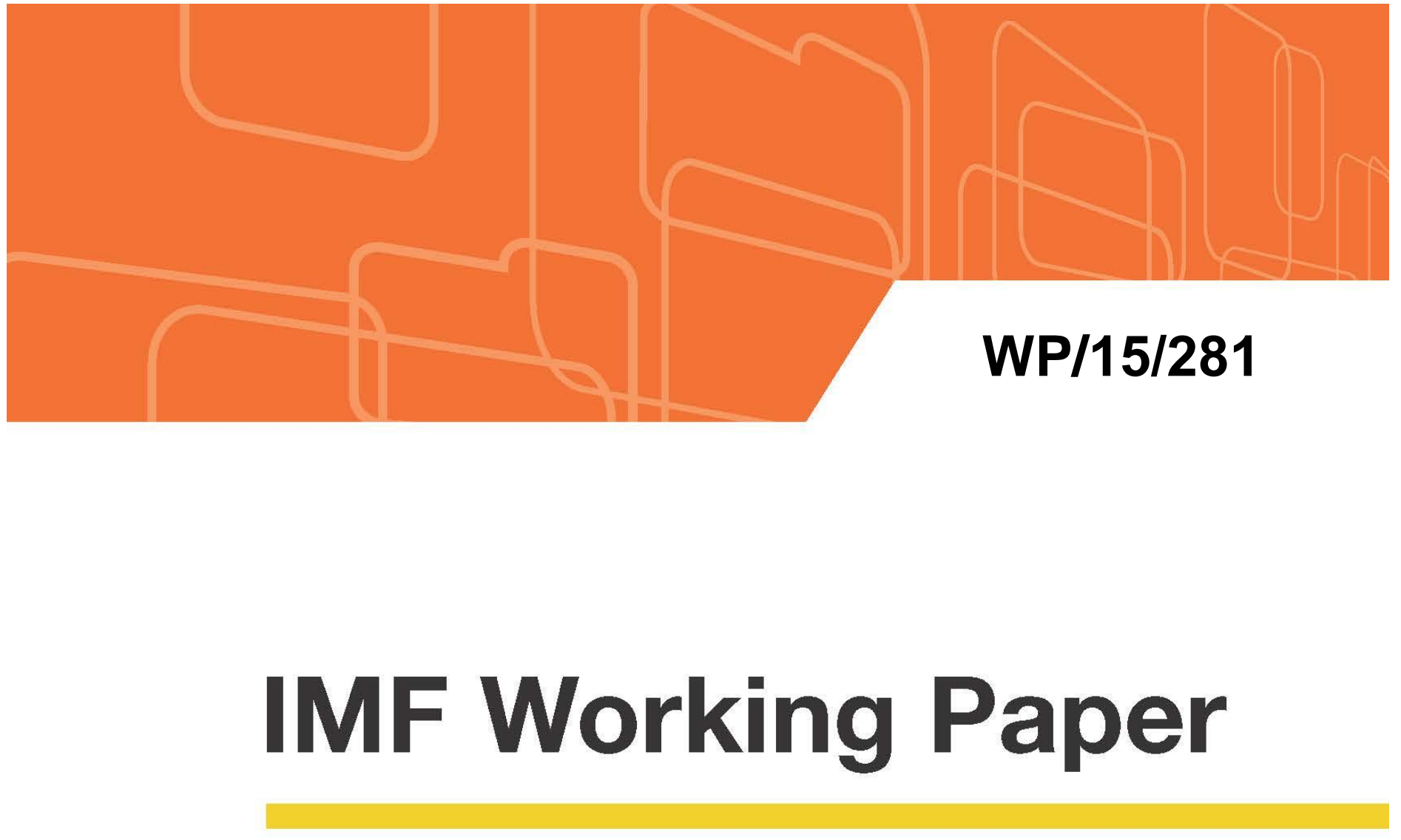

\title{
The Game of Anchors: Studying the Causes of Currency Crises in Belarus
}

By Alex Miksjuk, Sam Ouliaris, and Mikhail Pranovich 


\title{
IMF Working Paper
}

Institute for Capacity Development

\section{The Game of Anchors: Studying the Causes of Currency Crises in Belarus Prepared by Alex Miksjuk, Mikhail Pranovich, and Sam Ouliaris ${ }^{1}$}

\author{
Authorized for distribution by Ralph Chami
}

December 2015

\section{IMF Working Papers describe research in progress by the author(s) and are published to elicit comments and to encourage debate. The views expressed in IMF Working Papers are those of the author(s) and do not necessarily represent the views of the IMF, its Executive Board, or IMF management.}

\begin{abstract}
Belarus experienced a sequence of currency crises during 2009-2014. Our empirical results, based on a structural econometric model, suggest that the activist wage policy and extensive state program lending (SPL) conflicted with the tightly managed exchange rate regime and suppressed monetary policy transmission. This created conditions for the unusually frequent crises. At the current juncture, refocusing monetary policy from exchange rate to inflation would help to avoid disorderly external adjustments. The government should abandon wage targets and phase out SPL to remove the underlying source of the imbalances and ensure lasting stabilization.

JEL Classification Numbers: C32, E42, E52, E61, F31, F41

Keywords: currency crisis, exchange rate policies, fiscal policy

Authors’ E-Mail Addresses: A.Miksyuk@nbrb.by; mpranovich@jvi.org; souliaris@imf.org

\footnotetext{
${ }^{1}$ Alexei Miksjuk is a division chief at the National Bank of Belarus, Sam Ouliaris is a unit chief at the IMF Institute for Capacity Development and Mikhail Pranovich is an economist at the Joint Vienna Institute. The authors are grateful to Norbert Funke (JVI, Director) for supporting the scholar's visit of Alexei Miksjuk to the JVI in November 2014. The authors are grateful to Ralph Chami, Norbert Funke, Dmitry Murin, Martin Schindler and the members of the IMF's Belarus country team for comments and suggestions. We would like to thank Thomas Chapman for help in formatting the paper. All remaining errors are the authors' responsibility.
} 


\section{Contents}

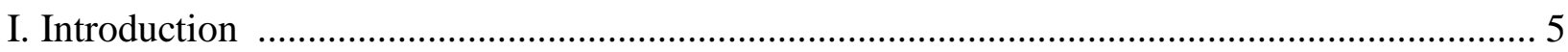

II. Overview of Macroeconomic Developments in Belarus: 2001-2014 ……………………....... 6

III. Methodology of Research ………………………….................................................. 9

A. Long-Run Equilibrium Relationships ……………….................................................. 10

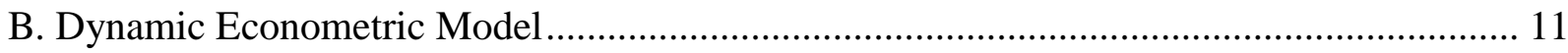

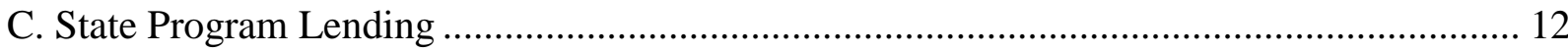

D. Monetary Policy Regime in Belarus: Closing the Model.................................................... 12

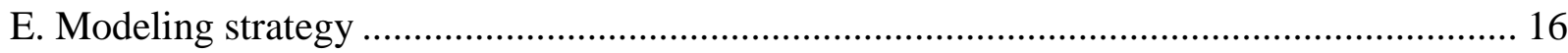

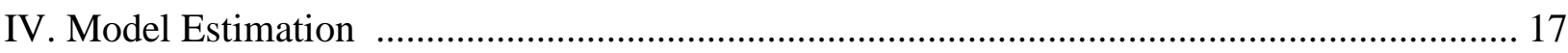

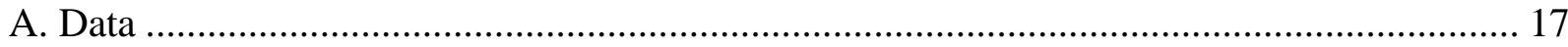

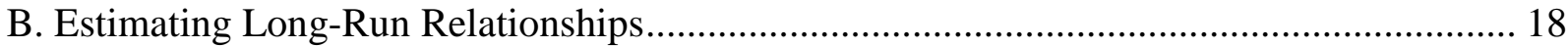

C. Estimating Short-Run Relationships ........................................................................... 19

D. Model Representation to Study Shocks: Ordering of Variables ........................................... 20

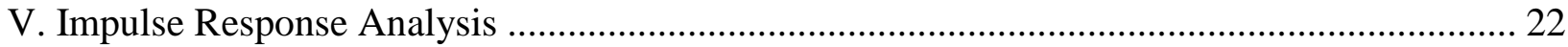

A. Monetary Policy Transmission: Policy Rate Shock ……………………............................ 22

B. Monetary Policy Transmission: Exchange Rate Shock ..................................................... 23

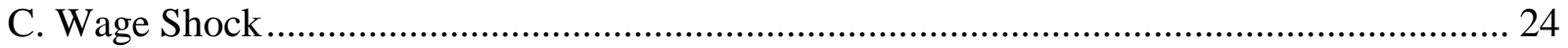

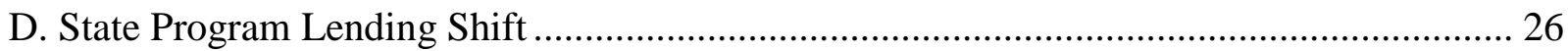

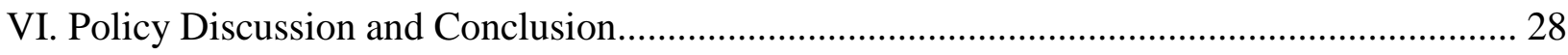

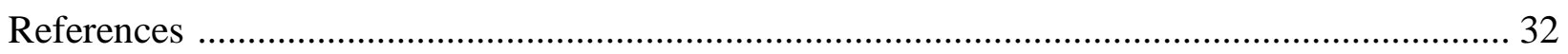

Figures

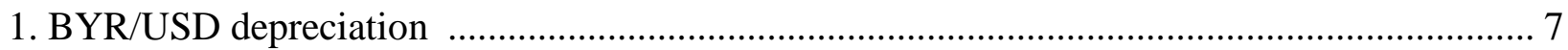

2. Current account balance and financing ......................................................................... 7

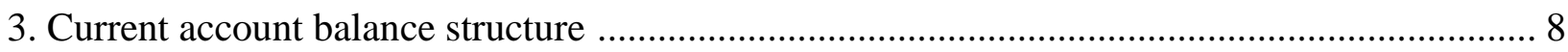

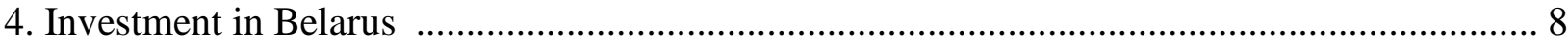

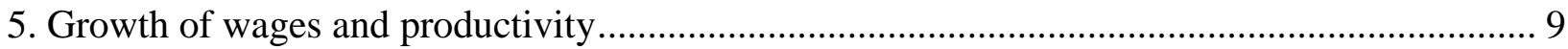

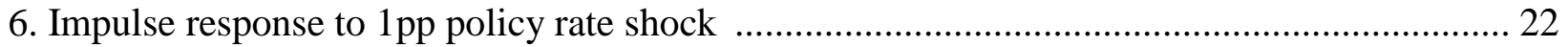

7. Impulse response to 1 percent devaluation shock.................................................................... 24 


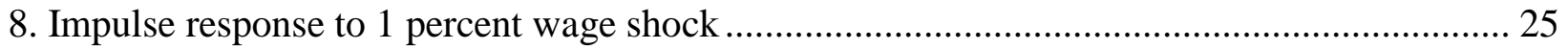

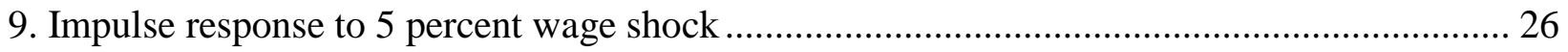

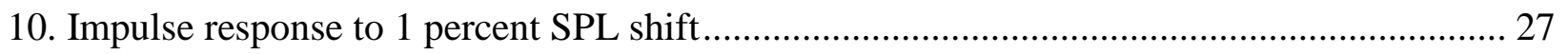

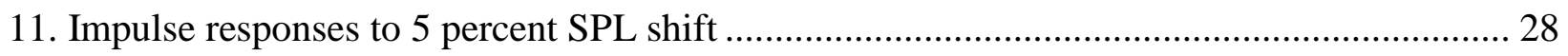

Appendices

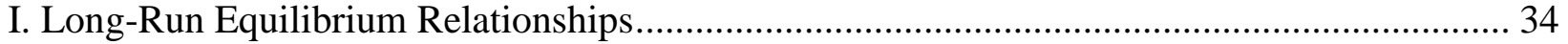

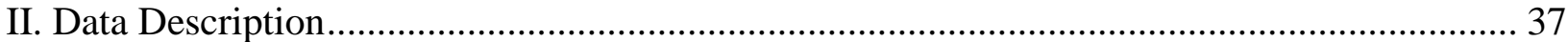

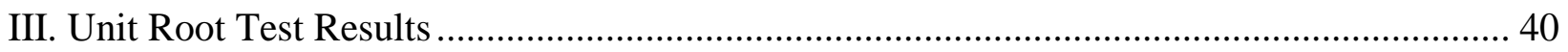

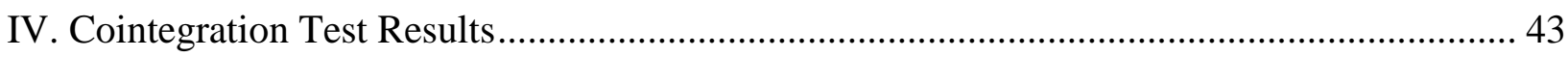

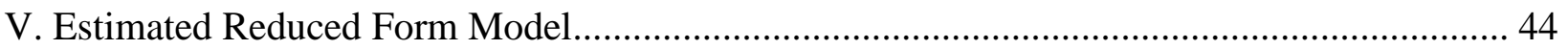

VI. Impulse Responses to Demand, Inflation and Monetary Base Shocks ................................... 46 


\section{INTRODUCTION}

By the beginning of 2000s, Belarus seemed to have settled on the main elements of its macroeconomic policy. Monetary policy focused on the stability of the nominal exchange rate, which was used as the nominal anchor. At the same time, to spur economic growth, the government introduced a number of state investment programs. The aim was to increase investment in sectors where the state remained a major stakeholder (agriculture, construction and heavy industry). Another important pillar of the economic policy was setting "wage objectives" that targeted the level of average wages. Moderating inflation and high economic growth in the first eight years of 2000s seemed to prove that the chosen economic policy worked. The 2009-2014 period, however, brought with it significant macroeconomic destabilization, including three currency crises in 6 years.

In this paper, we develop a macro-econometric model to study the causes of currency crises. After estimating the reduced-form model, we impose a structure that allows one to trace the impact of structural shocks of different magnitudes to wages and state program lending (SPL) on the economy and, in particular, on external balance.

Our main findings are the following:

- the quasi-fiscal wage and SPL policies appear inconsistent with the chosen monetary policy strategy based on the stabilized nominal exchange rate. We interpret this as a policy conflict at the institutional level: putting in place an alternative rigid nominal anchor (e.g., the wage level) and negating the efficiency of the exchange rate anchor;

- despite the low degree of capital mobility in Belarus, the impact of monetary policy via the interest rate channel remained weak, which contradicts the usual suggestion of the "impossible trinity". As widely discussed in the literature, such weakness may be attributed to structural failures in the financial system. In the specific case of Belarus, again, SPL could be the ultimate source suppressing market-based lending activity and the steering role of interest rates;

- the NBRB had little chance to defend the peg and withstand persistent increases in nominal wages and/or SPL given the weak interest rate instrument and rather limited foreign reserves. Ultimately, this led to unusually frequent currency crises. While small shocks could be absorbed without exchange rate realignment, shocks with a 
magnitude comparable to actual rates of increases in wages and SPL inevitably induced a currency crisis. The latter underscores a rather low degree of economic flexibility in Belarus.

These findings led us to two broadly unsurprising conclusions with respect to prevailing macroeconomic policy framework:

- adoption of a different monetary policy strategy with a more flexible nominal exchange rate would limit the scope for crisis-like adjustment;

- reducing and ultimately abandoning the activist wage policy and SPL would likely remove the core root for currency crises and will create setup for lasting internal and external stabilization.

In light of these recommendations, recent changes in macroeconomic policy - a plan to reduce SPL, a switch to monetary targeting and managed floating exchange rate in 2015 - are steps in the right direction.

The remainder of this paper is organized as follows. In the next section, we outline the key macroeconomic developments in Belarus during 2001-2014. In Section III we discuss methodology, model formulation and the estimation strategy. Section IV presents the data, the reduced form estimation and the identification assumptions used to study shocks to the economy. Section $\mathrm{V}$ describes the dynamic response of the economy to shocks to the nominal exchange rate, the interest rate, nominal wages and the SPL - which provides the basis for the policy discussion and recommendations presented in the final section.

\section{OVERVIEW OF MACROECONOMIC DEVELOPMENTS IN BELARUS: 2001-2014}

Like most transition economies in the region, after the turmoil of 1990s the Belarusian economy enjoyed a strong recovery. In 2001-2008, average annual growth exceeded 8 percent, while the Belarusian rubel (exchange rate) was broadly stable. Inflation, though, remained persistently high, falling below 10 percent y-o-y only three times during the period.

Figure 1: BYR/USD depreciation, q-o-q 
The situation changed dramatically after 2008. The country suffered three crises episodes in 6 years - in 2009, 2011 and 2014 (Figure 1). Prior to the each crisis, the current account deficit widened to more than 8 percent of GDP (Figure 2). Authorities attempted to preserve exchange rate stability through foreign borrowing and FX interventions, which

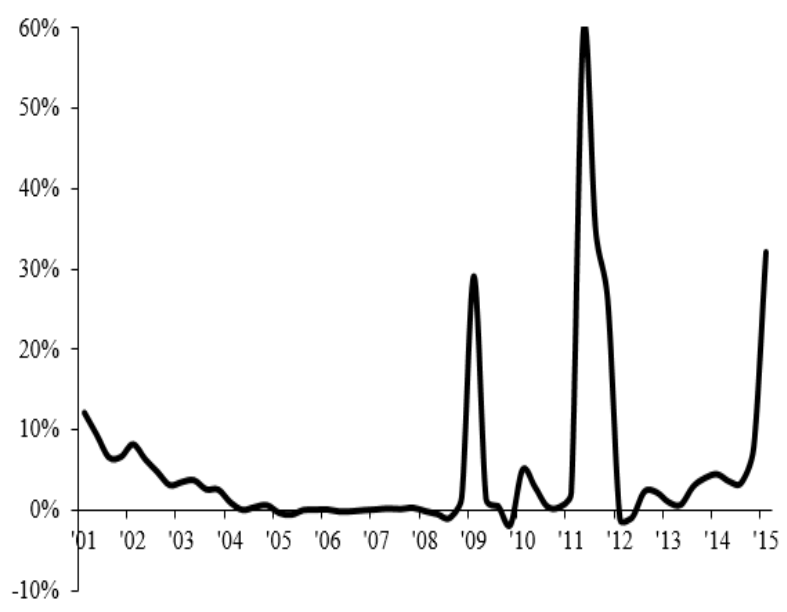
resulted in significant (and rapid) foreign debt accumulation.

Figure 2: Current account balance and financing

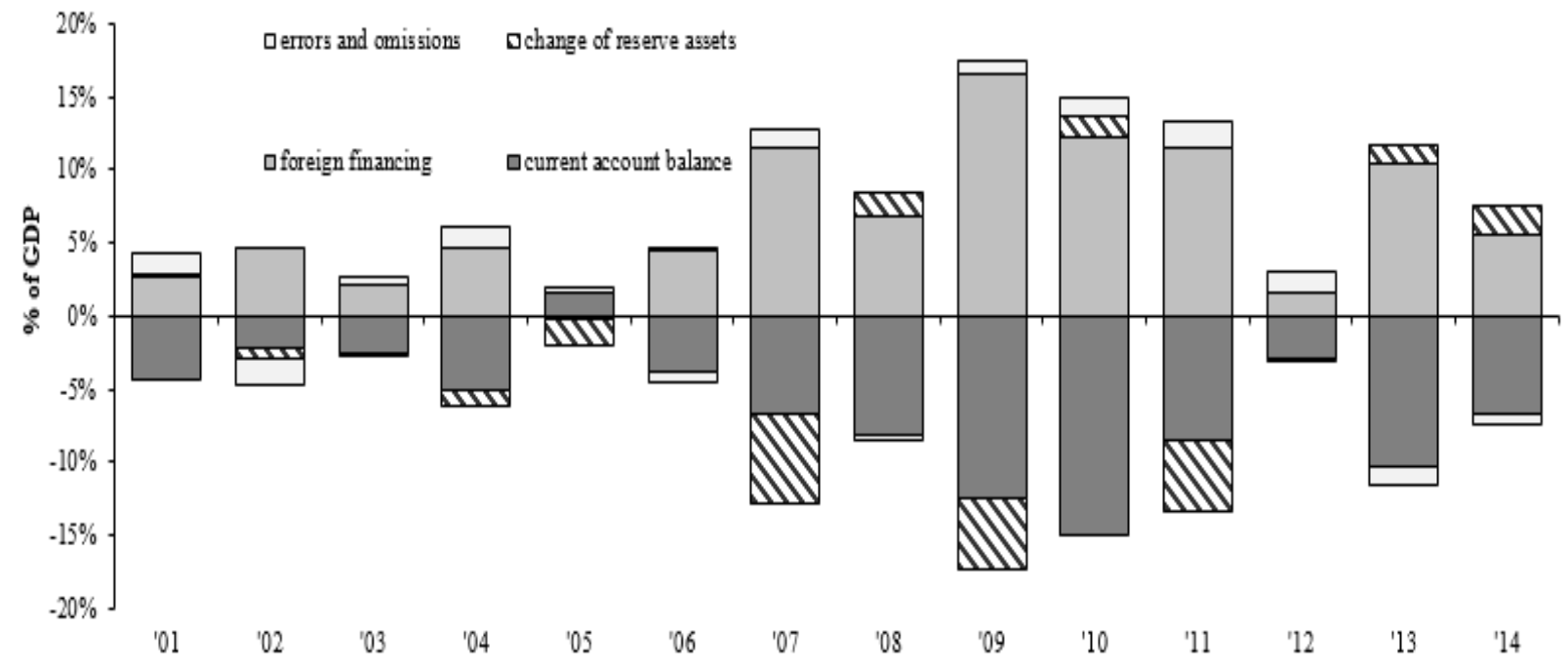

A series of the negative terms of trade shocks in energy products in particular led to deteriorating current account. Since 2007, however, energy trade deteriorated sharply as Russia moved towards higher energy prices for Belarus. Moreover, foreign trade excluding energy was also deteriorating, contributing to the imbalances, and net income payments increased to service the growing foreign debt (Figure 3). ${ }^{2}$

\footnotetext{
${ }^{2}$ Clearly, there were other shocks at play and figure 3 should be interpreted with caution. E.g., the shock to build-up precautionary import took place prior to switching to VAT collection on the destination country principle in trade with Russia in 2005. This shock deteriorated the current account deficit in 2004, but improved the balance to unusually positive level in 2005 .
} 
Figure 3: Current account balance structure

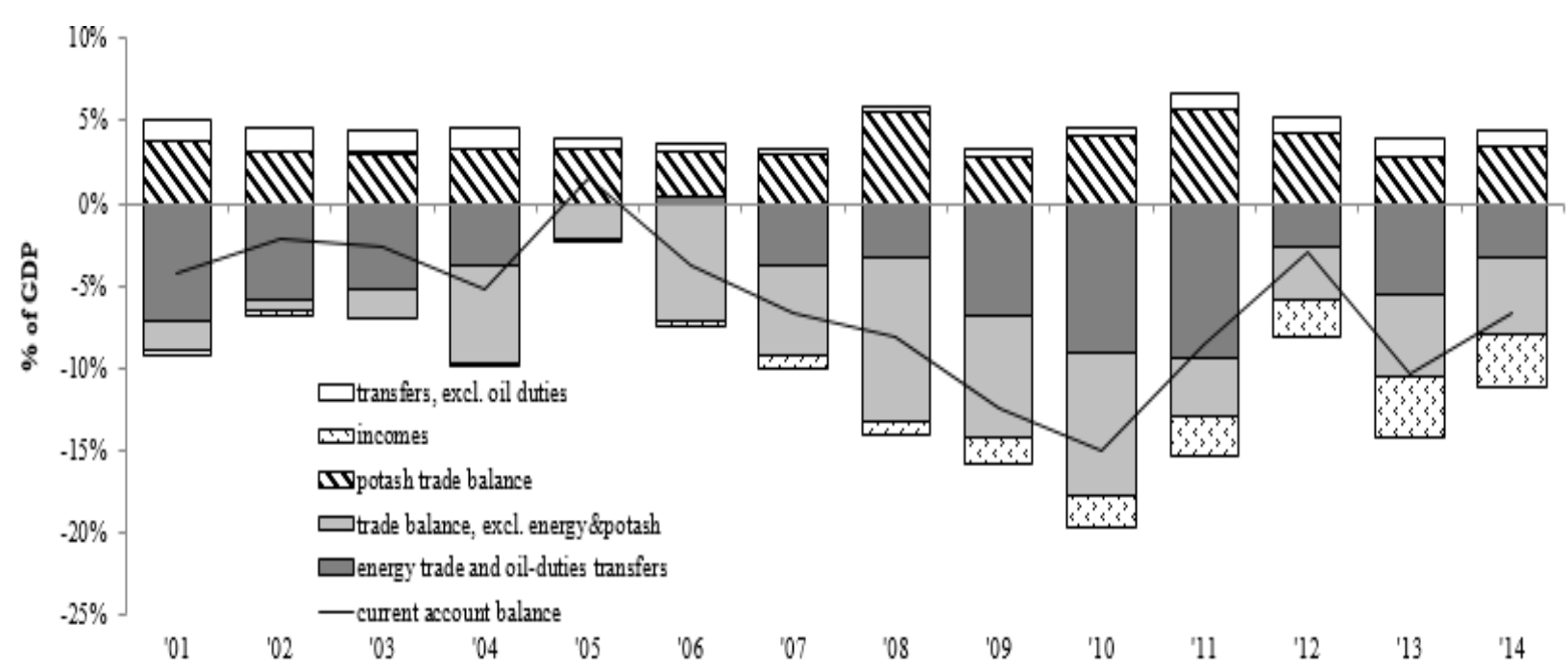

The economy was slow to adjust to permanent energy shocks and external imbalances remained persistent. To conjecture what prevented smooth adjustment of the economy to equilibrium we now analyse the economic policy pursued by the Government and the NBRB.

\section{State program lending}

Active investment policy was at the heart Figure 4: Investment in Belarus of the Belarusian economic growth model. Investment to GDP ratio remained high, with Belarus ranked around $10^{\text {th }}$ in the world since 2008 (Figure 4).

State program lending (SPL) was the main factor behind the investment surge. Banks provided non-market SPL loans to selected state-owned enterprises (SOEs). Although the SPL stimulated investments and output

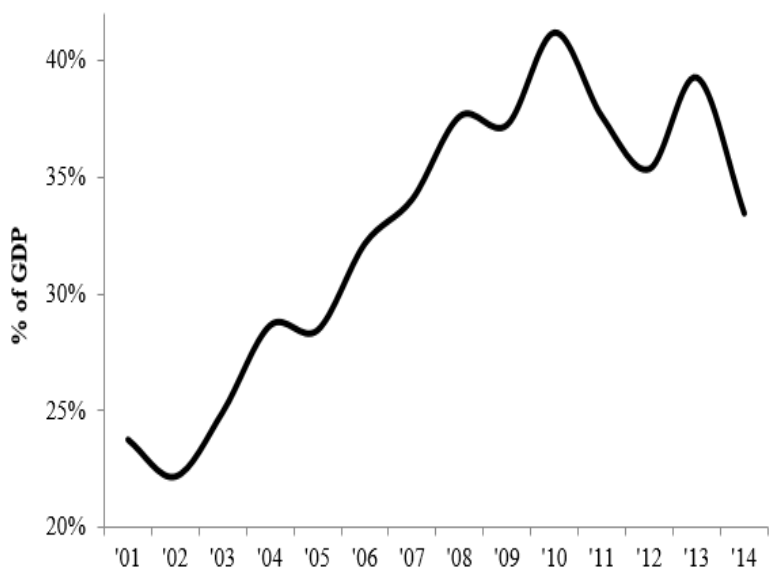
in the short-run, it also contributed to external and internal macroeconomic imbalances. ${ }^{3}$

\footnotetext{
3 The long-run effect of SPL on the economy is ambiguous. On one hand, SPLs speeded up capital accumulation. On the other hand, the loans contributed to distorted capital allocation, so that total factor productivity was declining (see Kruk and Haiduk (2013)).
} 


\section{Activist wage policy}

For most of 2000-2014, the Belarusian Government pursued activist wage policy by setting wage targets. The government also had administrative instruments necessary to achieve these targets, reflecting its dominant role in

economy.

Given standard spill-over effects to the private sector, the official wage targets were a key driver of wage dynamics in Belarus (Koczan, 2014). Real wage growth (deflated by CPI) exceeded productivity growth (Figure 5). ${ }^{4}$ This was likely a major costpush factor behind persistently high inflation and the loss of price competitiveness.

Figure 5: Growth of wages and productivity

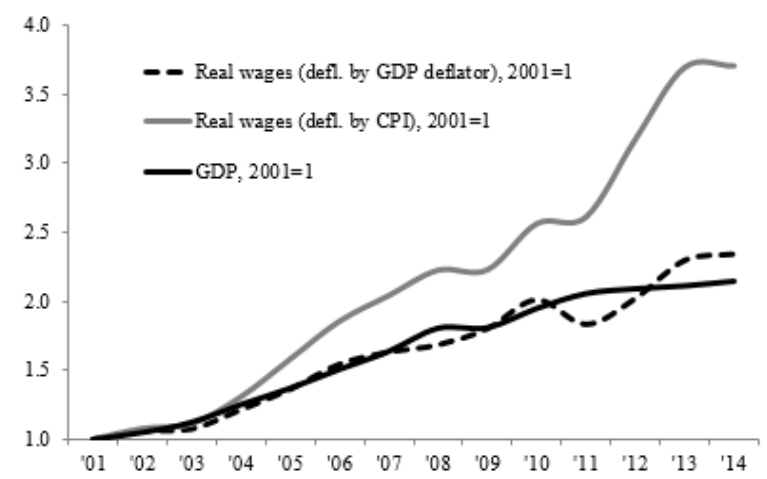

\section{Subordinated monetary policy and the case of (quasi-) fiscal dominance}

The crises episodes of 2009, 2011 and 2014 resemble $1^{\text {st }}$ generation of currency crises (Krugman, 1979; Flood and Garber, 1984). The policy setup was that of fiscal dominance, with a few important provisos. The government did not recognize the SPL in the budget expenditures, which gave rise to a quasi-fiscal component of the deficit. The activist wage policy was effectively a part of fiscal dominance: enterprises were directed to increase wages, which created deficits in the real sector that eroded working capital and increased demand for loans.

The quasi-fiscal policies substantially influenced the banking system and actions of the NBRB. The SPL and rapid wage increases consequently spurred demand for loans primarily supplied by the state-owned banks. In turn, this required timely closing of liquidity gaps and therefore created an interest rate inelastic demand for reserve money. The NBRB refinanced state-owned banks massively and in different forms: e.g., through liquidity provision at

\footnotetext{
${ }^{4}$ For the most part, the additional income obtained from export price increases covered wage increases, which implied that output prices were growing faster than CPI. Thus, real wage growth calculated using GDP deflator was in line with output growth until 2011, implying stable share of labor costs in total income (Figure 5).
} 
subsidized rates and reduction of reserve requirements versus such banks, resulting in a major increase in the money supply.

Such "refinancing" activities were at odds with the objective to preserve the exchange rate and achieving moderate inflation with two important consequences. The NBRB had to, first, extensively intervene in the FX market and, second, maintain high interest rates for the rest of the economy. The FX interventions helped at times stabilize both the reserve money and the exchange rate. However, as the official wage policy and SPL continued and the volume of foreign reserves diminished, the exchange market faced intensified speculative attacks.

While the potential sources of imbalances are clear (e.g., IMF, 2015), the size of their impact, their interaction and causality requires deeper analysis. We now construct a structural macroeconometric model to understand and quantify these effects.

\section{MeTHOdOLOGY OF RESEARCH}

Three important points need to be emphasized at this stage. First, we rely on macroeconometric modelling. Second, we construct a structural model to study repeating currency crises, investigate responses to shocks and the correction of the economy back to equilibrium. We formulate a system of long-run economic relationships that together describe a theoretically consistent Walrasian equilibrium for the economy. Our model enforces long-run neutrality of monetary policy, stability of economy's structure (shares of GDP components) and debt solvency. Third, we keep the model as small as possible for clarity of interpretation and for preserving estimation efficiency. However, the model should be rich enough for the purposes of our research. The latter precludes us from strictly following the structural cointegrating VAR approach as in Garrett et al. (2006), but we still use it as the guiding principle.

\section{A. Long-Run Equilibrium Relationships}

We use the theoretical model that is similar to Garrett et al. (2006) in core, but with some important differences (Appendix I). In the long-run, domestic output per capita grows in line with foreign output per capita, implying similar technological progress. Relative prices are 
determined by relative costs, with a Harrod-Balassa-Samuelson effect allowed for in the real exchange rate. The standard exchange equation holds in the money market.

The key difference is in the foreign exchange market equilibrium. The UIP, balancing capital flows, is a suitable equilibrium condition for advanced economies, but often proves inadequate for emerging markets. Therefore, we model financial flows using a standard portfolio balance approach by Branson and Henderson (1985) in which UIP deviations drive private net foreign liabilities. Volumes and prices of trade flows are modelled among other GDP expenditure components. The balance of payments identity takes trade and financial flows together and defines changes in FX reserves.

To analyse the central bank policy tools, we consider the money supply explicitly and model the money multiplier and the interest rate spread.

\section{B. Dynamic Econometric Model}

The dynamic model is in VECM form, namely:

$\Delta x_{t}=-\alpha \beta^{\prime} z_{t-1}+c_{0}+c_{1} t+\sum_{i=1}^{p} \Gamma_{i} \Delta z_{t-i}+\Lambda \Delta x_{t}^{*}+u_{t}$

supplemented with long-run identities

$x_{t}^{b} \equiv \Gamma^{b} z_{t}$,

where $z_{t}=\left(x_{t}{ }^{\prime}, x_{t}^{b_{1}}, x_{t}{ }^{*}\right)^{\prime}$ is the full vector of variables, $x_{t}=\left(\right.$ inv $_{t}, \operatorname{cons}_{t}^{p r}, \operatorname{cons}_{t}^{p u}, c_{t}^{e x}, c_{t}^{i m}, p_{t}^{i n v}$, $\left.p_{t}, p_{t}^{p u}, p_{t}^{e x}, p_{t}^{i m}, s_{t}, n f l_{t}, R_{t}, R_{t}^{i b}, w_{t}, m_{t}, b_{t}, i n v_{t}^{G o v}\right)^{\prime}$ is the vector of endogenous variables. It includes volumes of investment, private and public consumption, exports and imports, their respective prices, the nominal exchange rate, net foreign liabilities of private sector, credit and interbank real interest rates, nominal wages, money stock, monetary base and directed loans disbursement to GDP. Vector $x_{t}^{b}=\left(y_{t}, c_{t}, p_{t}^{y}, I n t_{t}\right)^{\prime}$ collects endogenous variables that are defined through balance identities and include output, absorption, GDP deflator and central bank FX interventions vis-à-vis the private sector. Vector $x_{t}{ }^{*}$ includes $n$ exogenous variables. In (1), $\beta$ is $(22+n) \times r$ matrix comprising $r$ cointegrating vectors $(0 \leq r \leq 18), \alpha$ is $18 \mathrm{x} r$ matrix of error correction coefficients, $\Lambda$ is $18 \times n$ matrix of coefficients of simultaneous effect of exogenous variables. Matrices $\left\{\Gamma_{\mathrm{i}}\right\}$ are $18 \times(22+n)$ of lagged effects, $p$ is the lag length, $c_{0}$ is fixed intercept, $c_{1}$ is the vector of deterministic trends, $\Gamma^{\mathrm{b}}$ is the matrix of 
parameters for identities. Reduced form shocks are $u_{t} \sim \operatorname{iid}(0, \Sigma)$ with $18 \times 18$ covariance matrix $\Sigma$.

Since Belarus is a small open economy, we treat $x_{t}{ }^{*}$ as strongly exogenous with respect to (1) and do not specify a partial model for $x_{t}{ }^{*}$, as it is not needed for impulse response analysis.

The long-run equilibrium relationships in Appendix I identify (2) and the 16 cointegrating relationships reflected in $\beta$. The short-run dynamics is initially given by the unrestricted VECM. Importantly, matrices $\alpha$ and $\beta$ can have a maximum $\operatorname{rank}^{5}$ of 18 , which is the number of variables in $x_{t}$. To fully identify the cointegrating vectors in $\beta$, we need to specify two policy elements explicitly set by the authorities ${ }^{6}$ : SPL and the nominal anchor. The form of the specification (in levels or in differences) will determine the rank of the matrices $(16,17$ or 18).

\section{State Program Lending}

As discussed in section II, SPL may be viewed as an economic policy tool used to boost investments. SPL volumes are based on long-term state programs adopted by the Government, but we found no regularity how the overall volume was determined. To model SPL dynamics, we focus on budget constraints and expect the ratio of directed lending disbursement to GDP $\left(i n v_{t}{ }^{G o v}\right.$ ) to be broadly stable, although we allow for linear trend in the data, persistence (autocorrelation) in the process and a structural break in 2011Q2:

$\operatorname{inv} v_{t}^{G o v}=c_{0}+c_{1} t+c_{0, b} d u m 11 q 2 x_{t}+c_{1, b} t \cdot d u m 11 q 2 x_{t}+\sum_{i=1}^{p} \gamma_{g, i} i n v_{t-i}^{G o v}+u_{t}^{G o v}$

\section{Monetary Policy Regime in Belarus: Closing the Model}

Thus far all the long-run relationships in the model are expressed in real and relative-price terms, ensuring long-run monetary policy neutrality. An equation for a nominal anchor needs

\footnotetext{
${ }^{5}$ Since the vector $z_{t}$ comprises $22+n$ time series, there could be up to $21+n$ cointegrating relationships. Up to 18 of these relationships may enter equation (1) in error-correction form

${ }^{6}$ The other policy variables are subordinate (implicitly determined in the model) and endogenously react to economic development.
} 
to supplement these relationships. Choosing the appropriate anchor depends on the policy strategy pursued by the central bank. De jure, the monetary policy regime in Belarus has been subject to frequent changes. Instead, we consider de facto monetary policy regime.

An important input for identifying the policy regime in Belarus is imperfect capital mobility. According to the "impossible trinity", imperfect capital mobility allows for corner possibilities of either inflation or exchange rate targeting. Yet another possibility is an intermediate strategy with two objectives: exchange rate and inflation targeting as is discussed in Ostry et al (2012).

The first corner option of inflation targeting and freely floating exchange rate does not seem to be relevant, since the NBRB has always tightly controlled the BYR/USD exchange rate. Therefore, a stabilized exchange rate is likely a part of one of the other two policy strategies.

If the NBRB targeted the exchange rate with no role for an inflation objective, then this would imply no reaction of the short-term interest rate or reserve money to inflation. At least one of the two conditions has to take place: (1) the NBRB used FX interventions to achieve the exchange rate objective; (2) the NBRB used short-term domestic interest rates or reserve money to achieve the exchange rate objective via affecting domestic money market conditions.

The intermediate policy strategy would likely take place if, in addition to steering the exchange rate, the NBRB attempted to adjust the interest rate in response to inflation deviating from an explicit or implicit objective. This strategy would, of course, be sustainable only if the inflation target $\left(\pi_{t}^{+}\right)$and the exchange rate target $\left(d e v_{t}^{+}\right)$were chosen consistently: $\pi_{t}^{+}-d e v_{t}^{+}-\Delta p_{t}^{*}=\Delta q_{t}^{h p}$.

To close the model and empirically identify the policy strategy and policy implementation, we formulate exchange rate, short-term-interest rate and domestic reserve money equations.

The exchange rate equation includes a linear trend to capture depreciation at a diminishing rate in 2001-2003. It also allows for zero depreciation in 2004-2013Q2 (interrupted by two currency crises episodes) and for roughly constant, positive rate of depreciation during 2013Q3-2014: 
$\Delta s_{t}=c_{2, s} c r i s_{t}+u_{t}^{s}+\left\{\begin{array}{c}-c_{1, s} t, \text { in 2001Q1-2003Q4 } \\ 0, \text { in 2004Q1-2013Q2 exc1.2011 } \\ c_{3, s}, \text { in 2013Q3-2014Q4 } \\ c_{4, s}, \text { in 2011 }\end{array}\right.$

Currency crises episodes are endogenous. We chose the interventions-to-reserves ratio lagged one period to capture the timing of the crisis. The start of a crisis and step-devaluation take place when this ratio exceeds a threshold 100 percent, which is equivalent to the amount of previous period FX interventions being larger than the amount of foreign reserves remaining in the end of that period. ${ }^{7}$ Devaluation is proportional to the size of real exchange rate misalignment $\left(\right.$ cris $\left._{\mathrm{t}}\right)$ :

cris $_{t}=\left\{\begin{array}{c}q_{t-1}-q_{t-1}^{h p}, \text { if }\left(-\operatorname{Int} t_{t-1}\right)>I R A_{t-1} \\ 0, \text { if }\left(-\operatorname{Int} t_{t-1}\right) \leq I R A_{t-1}\end{array}\right.$,

where $I R A_{t}$ is the volume of foreign reserves, $q_{t}^{h p}$ is the equilibrium real exchange rate.

Solving the monetary policy objective function gives the equation for the policy rate: ${ }^{8}$

$$
\begin{aligned}
& \Delta N R_{t}^{i b}=\chi_{1, i b} \text { Inty }_{t-1}+\chi_{2, i b}\left(\Delta p_{t-1}-\pi_{t-1}^{+}\right)+\chi_{3, i b}\left(y_{t-1}-\bar{y}_{t-1}\right)+\chi_{4, i b} \varepsilon_{t-1}^{s p r}-\alpha_{i b} \beta^{\prime} z_{t-1}+\ldots \\
& \ldots+c_{0, i b}+c_{1, i b} t+\sum_{i=1}^{p} \gamma_{i, i b} \Delta z_{t-i}+\lambda_{i b} \Delta x_{t}^{*}+u_{t}^{i b}
\end{aligned}
$$

where $\pi_{t}^{+}$is the target inflation rate, $\left(y_{t}-\bar{y}_{t}\right)$ is the domestic output gap (Appendix I).

Given (4), equation (6) allows for several strategies with a degree of control over the exchange rate. The pure exchange rate targeting would be consistent with $\chi_{1, \mathrm{ib}}<0, \chi_{2, \mathrm{ib}}=0$ and $\chi_{3, \mathrm{ib}}=0$, while $\chi_{1, \mathrm{ib}}=0$ and $\chi_{2, \mathrm{ib}}>0$ should hold for the intermediate strategy. The latter implies that the interest instrument focused on inflation and fully sterilized interventions - on

\footnotetext{
${ }^{7}$ We analysed possible values on a grid between 20 and 125 percent to calibrate this threshold. Under the chosen specification of 100 percent the NBRB conducts foreign interventions whenever it has enough foreign exchange to conduct interventions in the upcoming quarter. Once the reserves fall below the level of previous quarter's interventions, so that there is little chance to defend the peg in the next quarter, the NBRB gives up its interventions and allows the exchange rate to adjust. In this circumstances, foreign exchange reserves get fully exhausted during the crisis episodes.

${ }^{8}$ Detailed derivation of the theoretical model, including the monetary policy rule, may be found in the supplementary appendix at: http://www.jvi.org/about/staff-list/staff-detailview/member/mikhail-pranovich.html
} 
the exchange rate objective. We also allow for reacting to output gap in the intermediate strategy: $\chi_{3, \mathrm{ib}}>0$.

We conjecture that the NBRB could also attempt using the interest rate to affect both inflation and exchange rate objectives. In such a case (4), as well as $\chi_{1, \mathrm{ib}}<0$ and $\chi_{2, \mathrm{ib}}>0$ in (6) should hold. This would violate the "two objectives, two instruments" principle, because the interest rate is "distracted" to deal with the exchange rate objective. At best, pursuing two objectives would be ambiguous, signalling that the exchange rate objective might dominate inflation and providing no clear nominal anchor for expectations. At worst, the two objectives could be inconsistent, prompting the NBRB to give up on achieving one or the other.

Condition $\chi_{1, \text { ib }}<0$ in (6) may potentially mean two things: either the NBRB systematically used the money market rate to counteract the FX market imbalances (if interventions were fully sterilized) or the money market rate reacted endogenously to domestic liquidity conditions (if interventions were not fully sterilized). We cannot statistically differentiate between these two possibilities. Anecdotal evidence suggests that neither sterilization nor explicit weights on inflation and exchange rate objectives were the key elements of the NBRB practice. This makes endogenous reaction to changes in domestic liquidity a more plausible alternative.

Miksjuk and Pranovich (2007) show that during 2000-2014 interbank rates often deviated from the refinancing rate (the formal key policy rate in Belarus). ${ }^{9}$ Therefore, the latter rate did not fully signal the policy stance. Hence, we formulate the (6) for the overnight money market rate $\left(N R^{i b}\right)$. Lastly, in (6) we allow for the possibility that, rather than totally controlled by the NBRB, the rate was adjusting to the longer-term rates $\left(\chi_{4} \neq 0\right)$.

Similarly, domestic reserve money $(b)$ could either be used as a monetary policy instrument or be endogenously determined by banks' demand for liquidity:

\footnotetext{
${ }^{9}$ The overnight money market rate was often below the refinancing rate due to excess liquidity. There are also anecdotal evidence that the NBRB at times limited liquidity supply to alleviate pressures on the exchange rate, which elevated the money market rate above the refinancing rate.
} 


$$
\begin{aligned}
& \Delta b_{t}=\chi_{1, b} \operatorname{Inty}_{t-1}+\chi_{2, b}\left(\Delta p_{t-1}-\pi_{t-1}^{+}\right)+\chi_{3, b}\left(y_{t-1}-\bar{y}_{t-1}\right)+\chi_{4, b} \varepsilon_{t-1}^{b}-\alpha_{b} \beta^{\prime} z_{t-1}+\ldots \\
& \ldots+c_{0, b}+c_{1, b} t+\sum_{i=1}^{p} \gamma_{i, b} \Delta z_{t-i}+\lambda_{b} \Delta x_{t}^{*}+u_{t}^{b} .
\end{aligned}
$$

\section{E. Modeling Strategy}

We conjecture 17 long-run relationships to be tested for cointegration and estimated. ${ }^{10}$ As model (1) is difficult to estimate due to the usual curse of dimensionality, we use a two-stage estimation strategy. First, using the Engle-Granger approach, we test for cointegration and estimate the long-run relationships. The residuals of these relationships $\left(\varepsilon_{t}\right)$ augment the system of dynamic equations to the error correction form (1). Second, a short-run dynamic equation is estimated for every variable in (1). We impose restrictions to reduce the number of coefficients in (1): for $n f l_{t}, c_{t}^{e x}, c_{t}^{i m}, i n v_{t}, \operatorname{cons}_{t}^{p r}, \operatorname{cons}_{t}^{p u}, p_{t}^{i n v}, p_{t}^{p u}, p_{t}^{e x}, p_{t}^{i m}, R_{t}$, and $m_{t}$ we assume that if some variables enter a long-run relationship, they may affect each other's short-run dynamics. Coefficients on all the other variables are restricted to zero. ${ }^{11}$ In line with the $p$-star model, money demand may be partly driven by the output gap, so we include $\varepsilon_{\mathrm{t}-}$ $1^{\text {ygap }}$ in the model for $\Delta m_{t}$.

We do not restrict the dynamics for $\Delta p_{t}$ and $\Delta w_{t}$. Rational expectations imply restrictions on short-run parameters of VAR, but the form of these restrictions depends on the specific form of price-setting and wage-setting behaviour, which is unknown ${ }^{12}$. Similar to forward-looking policy rule, we leave the equations for $\Delta p_{t}$ and $\Delta w_{t}$ unrestricted. In this case the estimated model may still capture rational expectations, but this would come out as the result of empirical testing rather than a priori restrictions. Also, these expectations, of course, are subject to continuity of monetary policy: if the policy rule (6) - (7) changes, the parameters of price and wage dynamics may also change, which is in line with Lucas (1976) critique.

\footnotetext{
${ }^{10}$ Since we formulate exchange rate equation in $1^{\text {st }}$ differences rather than levels, this restricts the corresponding raw of matrix $\alpha$ to zero, so that the rank of $\alpha$ and $\beta$ is equal 17.

${ }^{11}$ If there is a cointegrating relationship: $x_{1 \mathrm{t}}-k_{1}-k_{2} x_{2 \mathrm{t}}-k_{3} x_{3 \mathrm{t}}=e_{1 \mathrm{t}}$, we include $e_{1 \mathrm{t}-1}$ and lags of $\Delta x_{1}, \Delta x_{2}, \Delta x_{3}$ in the set of regressors to model $\Delta x_{1}, \Delta x_{2}, \Delta x_{3}$. If a variable $x_{i}$ enters several long-run relationships, we use lags of variables from all these relationships in the dynamic equation for $x_{\mathrm{i}}$.

${ }^{12}$ Example of such restriction is provided in the supplementary appendix at: http://www.jvi.org/about/stafflist/staff-detailview/member/mikhail-pranovich.html.
} 
To decide the lag length and keep it small as possible we use specific-to-general approach: we subsequently increase lag order until the hypothesis of no autocorrelation cannot be rejected. After that, we excluded regressors that were not statistically significant. For most of the equations, the lag length remains 1 . We include dummies in only extreme cases of strong idiosyncratic shocks. ${ }^{13}$ The instrument $\Delta i n v_{t}{ }^{G o v}$ is as in (3). For $\Delta N R_{t}^{i b}, \Delta b_{t}, \Delta p_{t}$ and $\Delta w_{t}$ we used iterative approach, by augmenting the models with potential regressors and eliminating those that are not significant.

Lastly, we stack equations in a system, which is a restricted variant of (1), and re-estimate it simultaneously using SUR to improve efficiency of coefficient estimates.

\section{MODEL ESTIMATION}

\section{A. Data}

We use quarterly, seasonally adjusted data to estimate the model (see Appendix II). Most of the data is for 2001-2014, though some time series are available starting from 2002 . We do not consider the 1990s because of the stark difference in economic regimes. Broken production chains, hyperinflation, multiple exchange rates, strong regulation of prices, persistent deficits, etc., were characteristic for the early years of independence. These issues suggest that the economic mechanisms did not function well during this period, creating additional challenges for modelling economic relationships.

The augmented Dickey-Fuller test suggests that most time series possess unit roots (i.e., are I(1) processes), which allows us to investigate long-run (equilibrium) cointegrating equations and short-run dynamics in the error correction form (see Appendix III).

\footnotetext{
${ }^{13}$ Notation-wise, dummy $\operatorname{dum} A A q B x_{t}$ equals 1 starting from quarter B of the year $20 \mathrm{AA}$ and equal 0 before that. Similarly, dumAAqB$B_{t}$ equals 1 in quarter $\mathrm{B}$ of the year 20AA and equals 0 otherwise, $d u m A A q B_{-} C C q D_{t}$ equals 1 from quarter $\mathrm{B}$ of the year 20AA until quarter $\mathrm{D}$ of the year $20 \mathrm{CC}$ and equals 0 otherwise.
} 


\section{B. Estimating Long-Run Relationships}

So far in the long-run equilibrium relationships money exchange equation holds by construction, 3 equations involve stationary variables, while 13 equations are formulated specifically for $I(1)$ variables. Using the Engle-Granger test, we found that cointegration holds for all the 13 relationships (see Appendix IV):

$$
\begin{aligned}
& \left(y_{t}-y_{t}^{\text {world }}\right)-\left(e m p l_{t}-\text { pop }_{t}^{\text {world }}\right)-15.36-0.23\left(p_{t}^{\text {brent }}-p_{t}^{u s \_a p p a r e l}\right)=\varepsilon_{t}^{y} \\
& q_{t}^{\text {rus }}-1.40-0.80\left[\left(w_{t}-\left(y_{t}-e m p l_{t}\right)\right)-\left(s_{t}^{\text {rub }}+w_{t}^{\text {rus }}-\left(y_{t}^{r u s}-e m p l_{t}^{\text {rus }}\right)\right)\right]-0.20\left[p_{t}^{\text {im_oil }}-p_{t}^{\text {brent }}\right]=\varepsilon_{t}^{q} \\
& n f l_{t}-\left(p_{t}^{y}+y_{t}-s_{t}^{u s d}\right)+0.84-1.18\left[\ln \left(1+N R_{r}\right)-\ln \left(1+N R_{t}^{f}\right)-\Delta_{4} s_{t}^{u s d}\right] \cdot d u m 07 q 1 x c_{t}=\varepsilon_{t}^{n f l}, \\
& c_{t}^{e x}-\left[2 / 3 \text { ind }_{t}^{\text {rus }}+1 / 6 \text { ind } t_{t}^{e u}+1 / 6 y_{t}^{\text {world }}\right]+1.04 q_{t}-0.27=\varepsilon_{t}^{\text {cex }}, \\
& c_{t}^{i m}-c_{t}+7.61=\varepsilon_{t}^{c i m}, \\
& i n v_{t}-y_{t}+0.33+0.64\left[p_{t}^{i n v}-p_{t}^{y}\right]+0.42 R_{t}^{f}-0.32 i n v_{t}^{G o v}=\varepsilon_{t}^{i n v} \\
& \text { cons }_{t}^{p r}-\text { empl }_{t}-\left(w_{t}-p_{t}\right)+5.51-0.47\left[p_{t}-p_{t}^{y}\right]+0.14 R_{t}=\varepsilon_{t}^{\text {cons }}, \\
& p_{t}^{i n v}+3.04-0.56 p_{t}^{y}-0.44\left[p_{t}^{i m}+s_{t}^{u s d}\right]=\varepsilon_{t}^{p i n v}, \\
& p_{t}^{p u}+2.06-0.41 p_{t}-0.59 w_{t}=\varepsilon_{t}^{p p u}, \\
& p_{t}^{e x}-0.07-0.59\left[p_{t}^{\text {rus }{ }_{-} i}+\left(s_{t}^{\text {rub }}-s_{t}^{u s d}\right)\right]-0.41 p_{t}^{u s_{-} a p p a r e l}=\varepsilon_{t}^{\text {pex }}, \\
& p_{t}^{\text {im }}+1.55-0.23\left[p_{t}^{\text {rus_i }}+\left(s_{t}^{\text {rub }}-s_{t}^{\text {usd }}\right)\right]-0.25\left[p_{t}^{\text {eu_i }}+\left(s_{t}^{\text {eur }}-s_{t}^{\text {usd }}\right)\right]-0.52 p_{t}^{\text {us_apparel }}=\varepsilon_{t}^{\text {pim }}, \\
& m_{t}-b_{t}+0.93+0.43 r e q_{t}+0.45 N R_{t}-0.12\left[b_{t}-p_{t}\right]=\varepsilon_{t}^{b} \\
& \left(N R_{t}-N R_{t}^{i b}\right)-0.31+0.28\left(m_{t}-b_{t}\right)=\varepsilon_{t}^{s p r}
\end{aligned}
$$

In (8) potential output per capita in Belarus is growing in line with world output per capita, but oil price fluctuations may cause divergence in the paths. In (9) relative consumer prices 
are driven by relative costs, notably, by unit labour costs and oil prices, which captures the Harrod-Balassa-Samuelson effect and allows for oil price shocks. In (10) net foreign liabilities of private sector grow in line with GDP, but investors may take excessive long or short currency position given UIP deviations. The dummy variable $d u m 07 q 1 x c_{t}$ accounts for the fact that Belarus was not an active player in the international financial market before 2007, so that interest rate differentials could not have any effect. ${ }^{14}$ From (17) it follows that export prices that exclude energy and potash are completely driven by pricing-to-market principles, so that real exchange rate fluctuations do not affect them (in USD terms), but rather affect the gap between prices for domestic goods sold in Belarus and abroad. In (11), demand for export (excl. energy and potash) depends on foreign demand and the real exchange rate. In (12), demand for non-energy import depends on domestic absorption, while the real exchange rate effect turned out to be insignificant. Foreign prices completely drive import prices, as shown in (18). In (13)-(14), demand for investment and private consumption depends on income levels, their relative prices, and the real interest rates. However, the foreign-currency real interest rate matters for the former, since foreign currency loans are widely used to finance investment. Domestic currency dominates household lending, which makes domestic real interest rate significant in (14). Also, directed lending has strong impact on investment. In (15) the investment deflator is homogeneous with respect to GDP deflator and import prices. Similarly, in (16) public consumption deflator is homogeneous with respect to consumer prices and nominal wages. In the money supply equation (19), the money multiplier is determined by reserve requirements, nominal interest rate (which capture both real interest rate and inflation expectations prevailing in the economy) and the process of economy monetization (as reflected by real monetary base). Lastly, (20) represents the term structure of interest rates.

\section{Estimating Short-Run Relationships}

Full results of estimating (1) are in Appendix V. Here we focus on the estimated interest rate $\left(N R_{t}^{i b}\right)$ and reserve money $\left(b_{t}\right)$ equations to describe prevailing policy strategy and instruments.

\footnotetext{
${ }^{14}$ Also, like in real interest rates, the dummy is equal zero during and 1 year after currency crises (2009, 2011q2-2012q3), as we are unable to capture devaluation expectations at that period.
} 
We find that the short-term interest rate $\left(N R_{t}^{i b}\right)$ responds to both FX interventions $\left(\right.$ Inty $\left.y_{t}\right)$ and inflation deviating from the target $\left[\Delta_{4} p_{t}-\pi_{t}^{+}\right]$: in (6), $\chi_{1, \mathrm{ib}}<0$ and $\chi_{2, \mathrm{ib}}>0$. The output gap $\left(\varepsilon_{t}^{y g a p}\right)$ is not statistically significant, i.e. $\chi_{3, \mathrm{ib}}=0$. We interpret this as evidence that the NBRB attempted to pursue a strategy with two objectives - inflation and exchange rate. However, as discussed in section III.D, interventions were not sterilized and the interest rate was reacting to interventions-driven changes in domestic liquidity, i.e. the interest rate did not focus on inflation alone.

The reserve money $\left(b_{t}\right)$ is determined by demand for liquidity $\left(\varepsilon_{t}^{b}\right)$, non-sterilized interventions (Inty $)$ and money demand $\left(\varepsilon_{t}{ }^{v}+\varepsilon_{t}^{\text {ygap }}\right)$. Similar to the impact of FX interventions on the money market interest rate, $\chi_{4, b}>0$ and statistically significant indicates that interventions impacted domestic liquidity conditions. Given that and statistically insignificant $\chi_{2, \mathrm{~b}}$ and $\chi_{3, \mathrm{~b}}$, domestic reserve money in (7) is most likely endogenous and hence not an active policy instrument.

We also find a structural break in SPL dynamics in 2011Q2, but no evidence of breaks in other equations. Thus, we cannot reject the hypothesis of super exogeneity of SPL with respect to the remaining equations (Engle et al., 1983): the change in SPL behaviour does not change the other relationships in the model, so that we can use the model to study impulse response analysis to permanent SPL shifts.

\section{Model Representation to Study Shocks: Ordering of Variables}

The covariance matrix of shocks $\Sigma$ in the reduced form model is not diagonal, i.e. some shocks are simultaneously correlated. Thus, we need to sequence variables and apply Choleski decomposition to $\Sigma$ to identify the model and study responses to structural shocks.

Authorities set targets for some of the variables well in advance. The NBRB always decided an explicit or implicit objective for BYR/USD exchange rate $\left(s_{t}{ }^{u s d}\right)$. The 5-year state programs or annual plans determined SPL $\left(i n v_{t}{ }^{G o v}\right)$ and targets for wages $\left(w_{t}\right)$. Therefore, we

assume $s_{t}^{u s d}$, inv $v_{t}^{\text {Gov }}$ or $w_{t}$ do not respond to other variables' shocks. Additionally, $s_{t}{ }^{u s d}$ is ordered first, i.e. it does not simultaneously respond to $i n v_{t}^{G o v}$ or $w_{t}$, but the reverse causality is possible (e.g., in the event of a currency crisis). Also, we assume $i n v_{t}^{G o v}$ precedes $w_{t}$. 
To sequence the rest we consider two options. First, the policy interest rate $\left(N R_{t}^{i b}\right)$, simultaneously affects demand components $\left(\operatorname{inv}_{t}, \operatorname{cons}_{t}^{p r}, \operatorname{cons}_{t}^{p u}, c_{t}^{e x}, c_{t}^{i m}\right)$, prices $\left(p_{t}^{i n v}, p_{t}\right.$, $\left.p_{t}^{p u}, p_{t}^{e x}, p_{t}^{i m}\right)$ and monetary aggregates $\left(m_{t}, b_{t}\right)$. In such a case, the impulse responses were anomalous: higher interest rate leads to higher output and inflation, which is a "price puzzle". ${ }^{15}$ Second, the policy rate is ordered after demand components, prices and money. Impulse responses were adequate in that case and we, therefore, prefer this ordering. Also, we assume that the policy rate precedes the rate for loans $\left(N R_{t}\right)$.

We order $N R_{t}^{i b}$ prior to $n f l_{t}$. In this case, a positive foreign financing shock decreases the interest rate simultaneously, while positive shock to interest rates induces capital inflow. ${ }^{16}$

Next, we order the demand components $\left(\operatorname{inv}_{t}, \operatorname{cons}_{t}^{p r}, \operatorname{cons}_{t}^{p u}, c_{t}^{e x}, c_{t}^{i m}\right)$, prices $\left(p_{t}^{i n v}, p_{t}, p_{t}^{p u}\right.$, $\left.p_{t}^{e x}, p_{t}^{i m}\right)$ and monetary aggregates $\left(m_{t}, b_{t}\right)$. Since we consider money as endogenous and demand driven, rather than a policy instrument, we assume demand or prices simultaneously affect money aggregates, but money affect macroeconomic indicators only with a lag. We remain agnostic whether prices simultaneously affect demand components or vice versa and use the former ordering. However, for robustness we check the ordering of demand components prior to prices: results are broadly similar in both cases.

As noted in, for example, Garratt et al (2006), when using the Choleski decomposition, impulse responses differ only with respect to the subset of variables before and after the shocked variable, but not with respect to ordering within the subsets. ${ }^{17}$ Thus, for the purpose of our analysis we use arbitrary sequencing: foreign prices come before domestic in $\left(p_{t}^{i m}, p_{t}^{e x}\right.$, $\left.p_{t}, p_{t}^{i n v}, p_{t}^{p u}\right)$, export precedes domestic demand components followed by import in $\left(c_{t}^{e x}\right.$, $\left.\operatorname{cons}_{t}^{p u}, \operatorname{cons}_{t}^{p r}, i n v_{t}, c_{t}^{i m}\right)$. Also, money precede reserve money $\left(m_{t}, b_{t}\right)$, as we assume the latter is driven by demand for liquidity.

Taking everything together, we obtain the following ordering: $s_{t}^{u s d}$, inv ${ }_{t}^{\text {Gov }}, w_{t}, p_{t}^{\text {im }}, p_{t}^{e x}, p_{t}$, $p_{t}^{i n v}, p_{t}^{p u}, c_{t}^{e x}, \operatorname{cons}_{t}^{p u}, \operatorname{cons}_{t}^{p r}, \operatorname{inv}_{t}, c_{t}^{i m}, m_{t}, b_{t}, N R_{t}^{i b}, N R_{t}, n f l_{t}$.

\footnotetext{
${ }^{15}$ See, for example, Sims (1992), Eichenbaum (1992).

${ }^{16}$ If, in contrast, $n f l_{t}$ precedes $N R_{t}^{i b}$, then a positive foreign financing shock led to higher money market rate. This is not consistent with the easing of monetary policy in reaction to capital inflows or decreasing money market rate, when domestic liquidity increases after the non-sterilized FX interventions.

${ }^{17}$ For example, to study the effect of the exchange rate devaluation on demand, the ordering of the exchange rate prior to demand or after it is important, but not the ordering within the set of demand components.
} 


\section{IMPULSE RESPONSE ANALYSIS}

To examine the features of monetary policy transmission mechanism prevailing in Belarus during 2001-2014 and some of the long-run properties of the model, we start with impulse responses to the policy rate and the exchange rate shocks. Then we turn to impulse responses to wage shocks and shifts in SPL, which are the focal points of our research. For the sake of brevity, we report the usual demand and supply as well as monetary base shocks in Appendix VI: the dynamic responses are standard, with demand and monetary base shocks being shortlived and of limited effect.

\section{A. Monetary Policy Transmission: Policy Rate Shock}

The effect of the 1 percentage point policy rate shock on the economy is negligible (Figure 6), which confirms earlier findings of weak interest rate channel in Belarus (Kallaur et al., 2005; Horvath and Maino, 2006). Given the small effect on demand and output, the interest rate effect on wages and prices is also limited. The policy rate is remarkably persistent with a half-life of five years. In the long-run, real variables remain unaffected according to monetary policy neutrality. Also, stock equilibrium is ensured. The ratio of net foreign liabilities to GDP gradually returns to its long-run level, in line with the foreign debt solvency constraint. The money-to-GDP ratio remains at the initial level.

Figure 6: Impulse response to $1 \mathrm{pp}$ policy rate shock

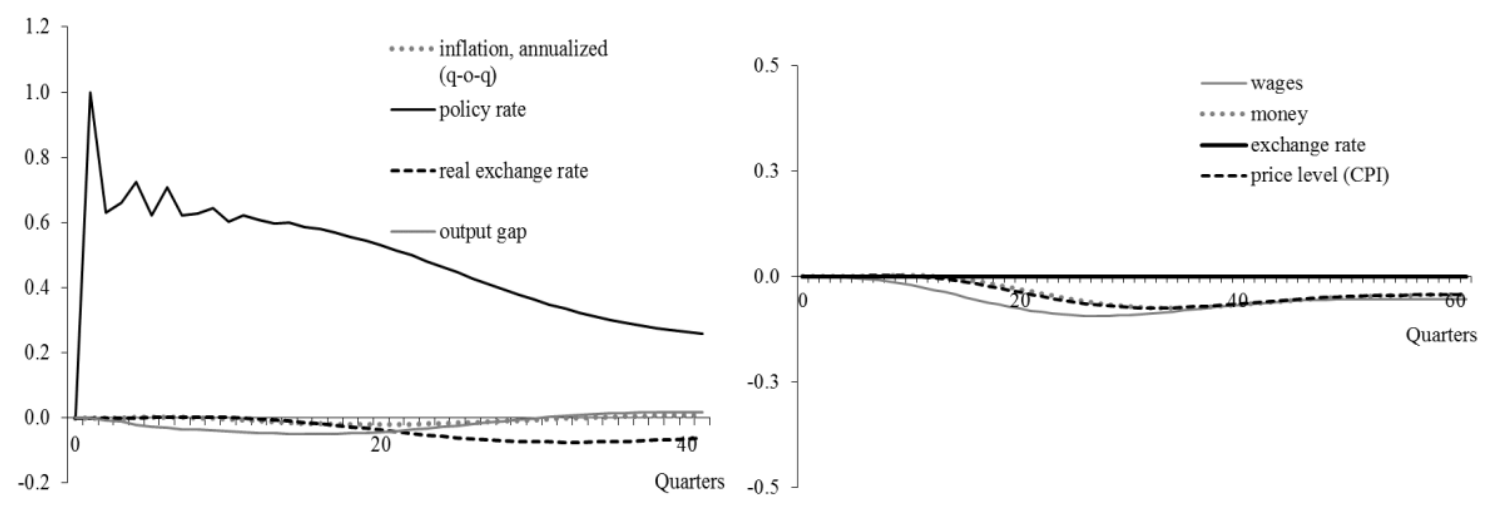



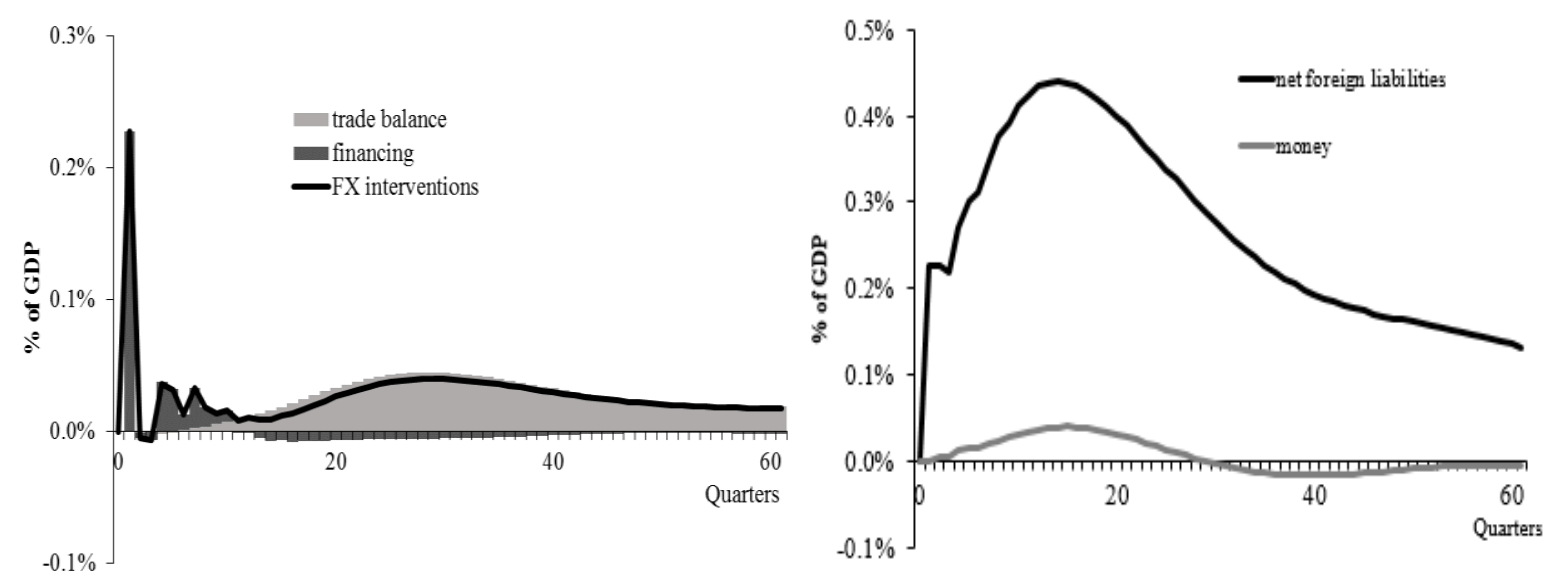

\section{B. Monetary Policy Transmission: Exchange Rate Shock}

The 1 percentage point nominal depreciation (Figure 7) decreases the real exchange rate. This switches demand to domestically produced goods and fuels export-driven expansion and reduction in import. Foreign trade improves and offsets initial capital outflow: the NBRB intervenes in the FX market and accumulates reserves equivalent to about 0.25 percent of GDP during the second year. ${ }^{18}$ Output peaks at 0.7 percentage points within a year. Increased activity leads to higher wages. The latter and higher imported inflation puts upward pressure on prices, which in three years converge to a new nominal level anchored by the exchange rate. Monetary policy is passive: the money market interest rate does not initially react to the shock, and the money stock adjusts to the new price level with a lag. Increasing prices gradually erase initial competitiveness gains, and reverse the dynamics of output and foreign trade. Eventually, all the gaps of real variables close, while prices, wages and money are at a new nominal level anchored by the exchange rate. The long run monetary policy neutrality and stock equilibrium take place again.

\footnotetext{
${ }^{18}$ Note here and below that the ratios of trade balance, foreign financing and interventions to GDP are provided in the graphs in per quarter terms. This implies that interventions to GDP per year is the average (rather than the sum) of quarterly values.
} 
Figure 7: Impulse response to 1 percent devaluation shock
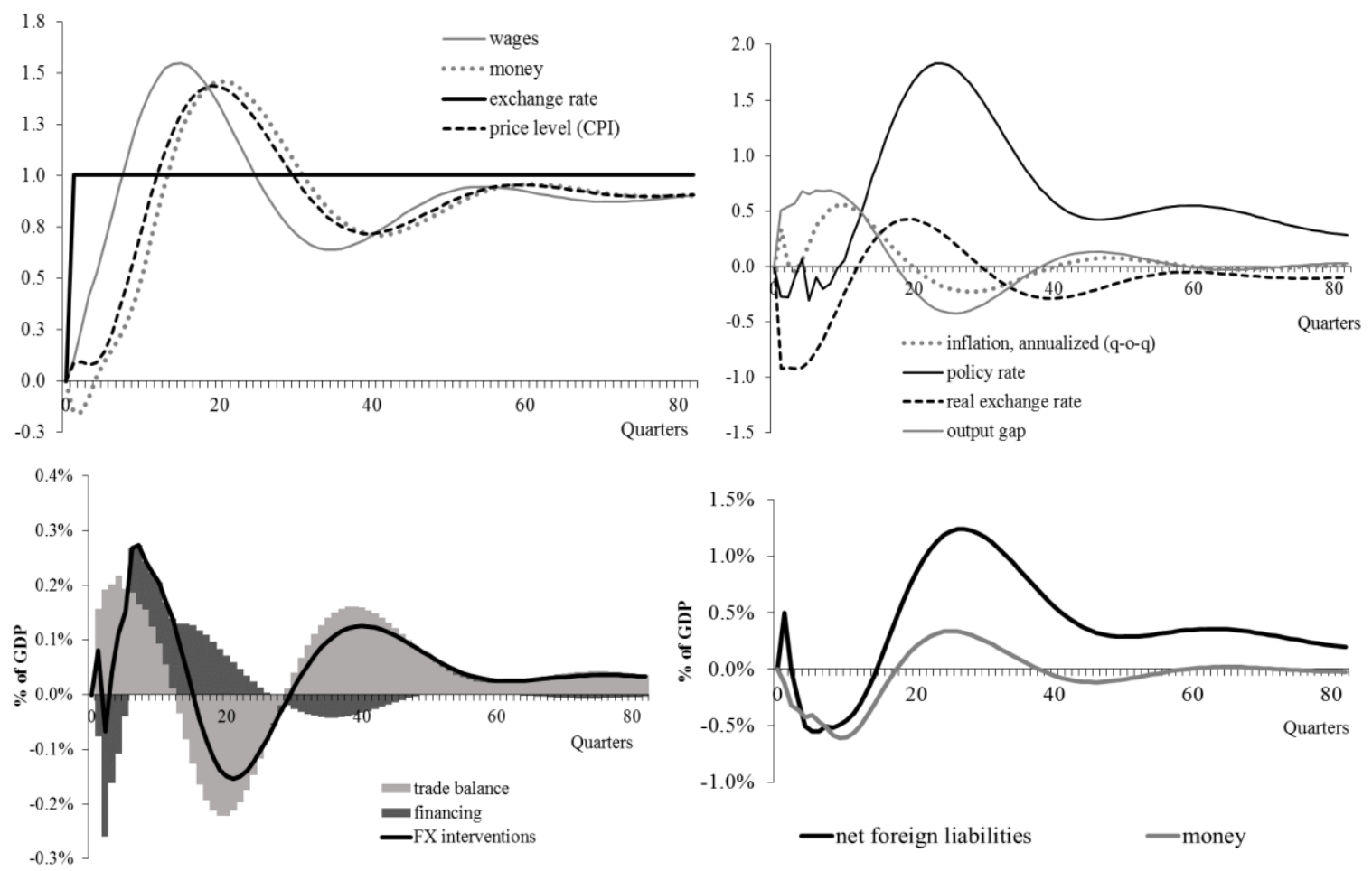

\section{Wage Shock}

In this section, we analyse the consequences of the government's activist wage policy, which is one of the focal points of our paper. We consider two kinds of shocks to nominal wages: a relatively "small" 1 percent shock and a "moderate" 5 percent shock. ${ }^{19}$ These shocks have rather different consequences for economic dynamics and the nominal exchange rate anchor.

The 1 percentage point nominal wage shock (Figure 8) leads to an immediate foreign finance outflow of 0.4 percent of annual GDP, which could be attributed to household purchase of foreign currency. The nominal wage hike induces gradual price increase (with a half-year lag). In response, wages increase even higher, implying strong real wage persistence as the Government attempts to fulfil the wage targets. The real wage gap remains positive for almost three years, while inflation stays above its normal level. The output gap peaks at 0.7

\footnotetext{
${ }^{19}$ Since 2005 , nominal wages grew by $2-6.5 \%$ per quarter (corrected for seasonal fluctuations). In a number of quarters nominal wage growth accelerated above 6.5\%, in particular: 2005Q4, 2006Q1 and 2008Q1 - about $7.5 \%, 2010 \mathrm{Q} 2$ and 2010Q3 - about 8\% and picking up to 12.5\% in 2010Q4. Wage growth conformed hyperinflation in 2011, but remained high in 2012: at 21.5\% in 2012Q1 and 11.5\% in 2012Q2 and 2012Q3.. These wage spikes provided a rough idea for calibrating nominal wage shocks in our work.
} 
percent after $1 \frac{1}{2}$ years, as increasing wages stimulate consumption. However, as the real exchange rate appreciates, demand switches somewhat to foreign goods. The output gap turns negative after three years, while foreign trade balance deteriorates and puts pressure on the FX market.

In response to higher inflation and adverse FX market developments, the policy rate gradually increases by 4.5 percentage points and remains above its neutral level for several years. The policy reaction only partially offsets pressure on FX reserves. The NBRB has to sell 1.9 percent of GDP worth of reserves to finance trade deficit and preserve exchange rate stability.

Figure 8: Impulse response to 1 percent wage shock
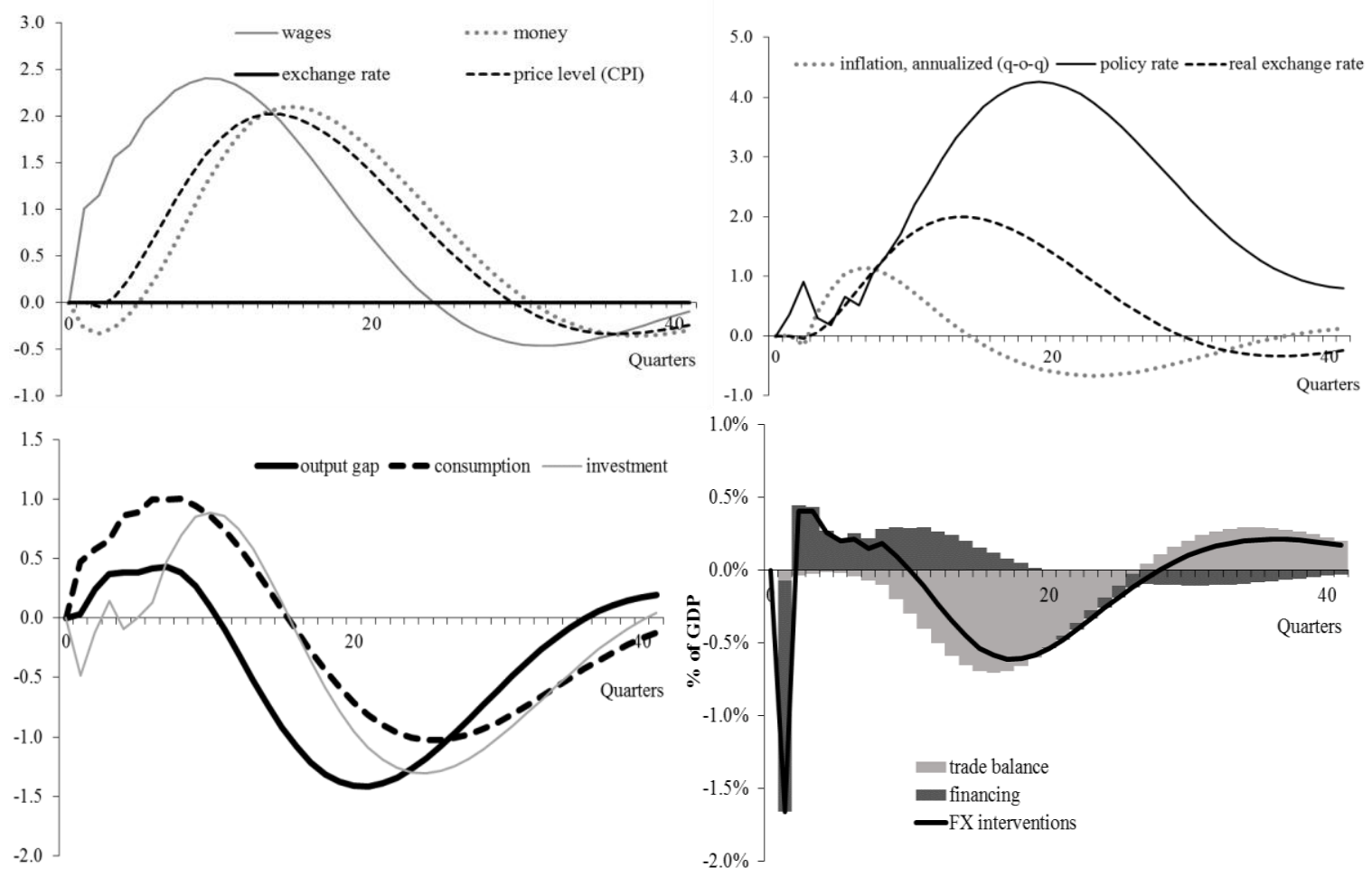

We note, however, that foreign reserves in Belarus never reached a conventional minimum standard of three months of imports. During 2001-2014, the volume of reserves was fluctuating between 2.8 and 13.5 percent of GDP. Only about half of that amount was liquid and could be readily used for FX interventions, with the rest kept in gold and SDR.

We now simulate a 5 percent nominal wage shock, given disposable foreign reserves at 5 percent of GDP (Figure 9). The dynamics of economy is starkly different compared to the 
"small” shock scenario. Increasing domestic prices put pressure on competitiveness and leads to a mounting current account deficit. Foreign reserves deplete in four years, the currency crisis follows and the NBRB is forced to devalue to restore the external balance. The 15 percent devaluation improves competitiveness, stabilizes the FX market and stimulates output. In the longer-run, wages and prices converge to the new level of the nominal exchange rate.

Figure 9: Impulse response to 5 percent wage shock (Disposable reserves $=5$ percent of GDP)
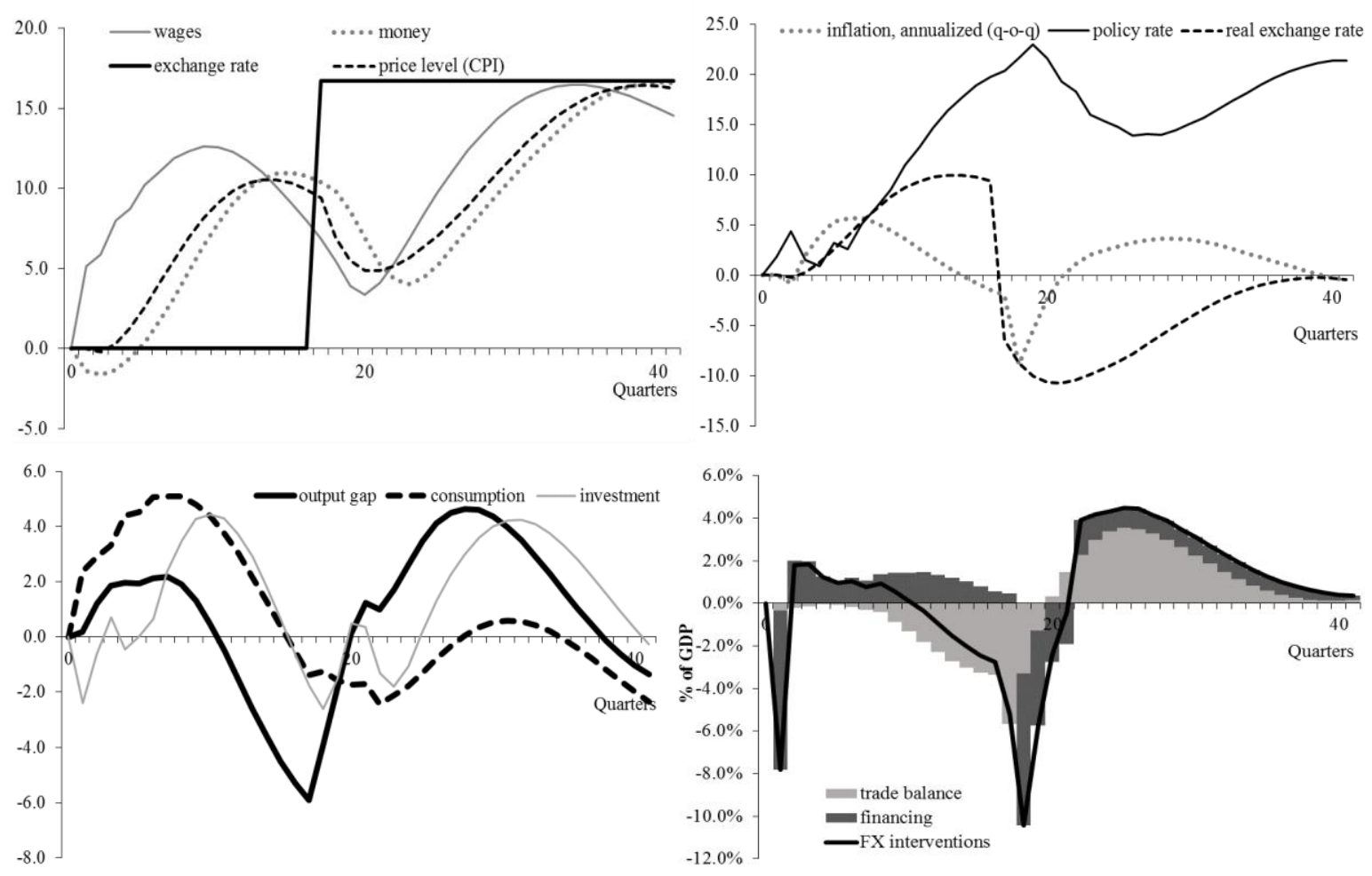

\section{State Program Lending Shift}

Similar to the case of wages we now study shifts in SPL of two magnitudes -1 and 5 percentage points. Increase in SPL by 1 pp shifts investments upwards and opens positive output gap. The latter pushes wages and prices up, causing an appreciating real exchange rate and deteriorating foreign trade. In response to these adverse developments, monetary policy tightens (interest rates increases), pushing output, prices and wages to the neutral level.

Eventually the permanent increase in SPL shifts demand composition from consumption towards investments. The market interest rate increases permanently by about 1.5 percentage points to accompany this shift. Inflation and real wages remain elevated for a number of years and converge to the long-run levels with significant lags. Along this convergence path, 
the exchange rate remains appreciated and the foreign trade balance remains negative, which requires extensive FX interventions ( 2 percent GDP) to support the peg. In the long-run, aggregate output returns to its potential level. ${ }^{20}$

Figure 10: Impulse response to 1 percent SPL shift
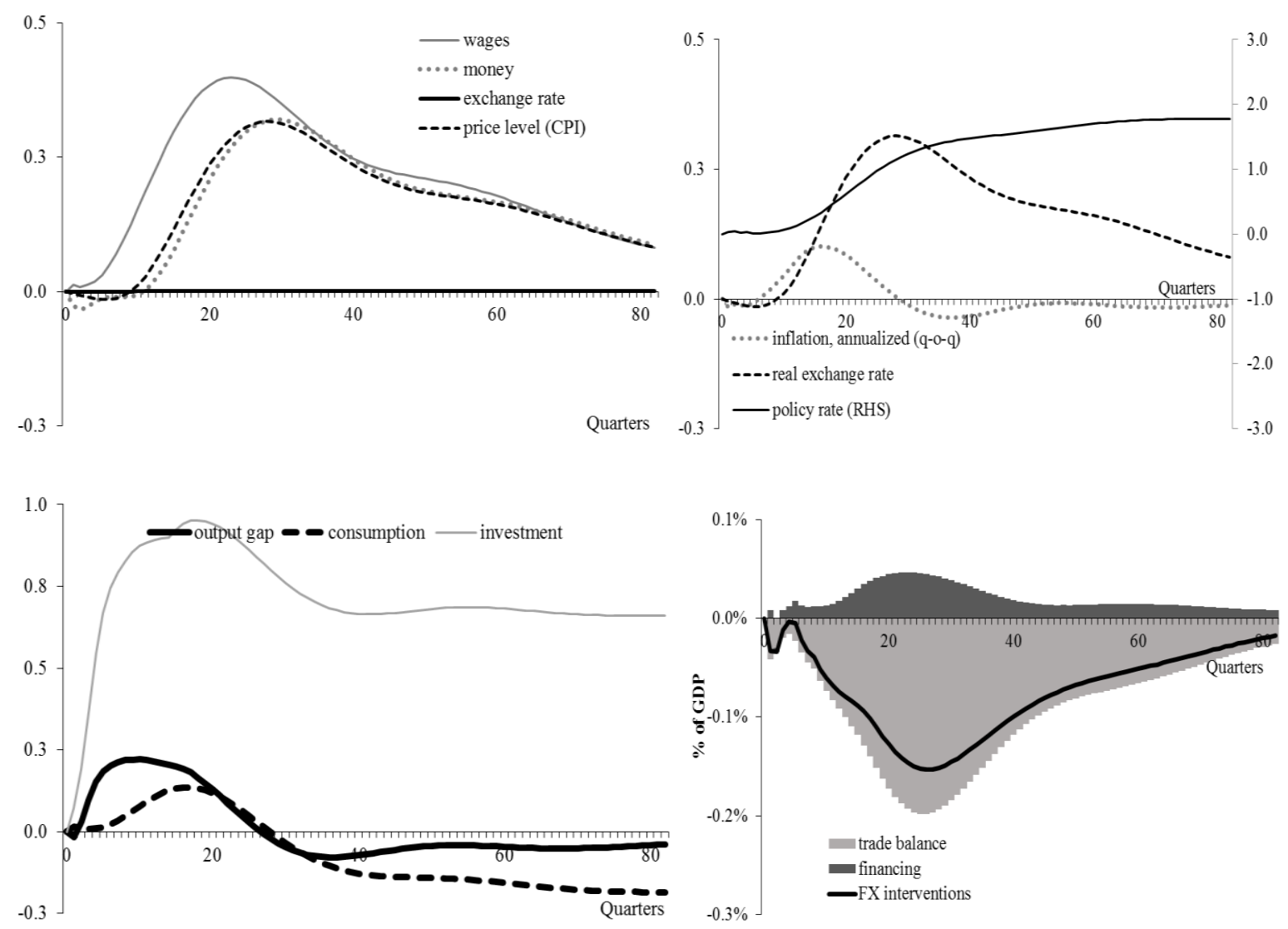

Given low FX reserves, it is likely that equilibrium restores via different mechanics if a larger SPL shift takes place. To illustrate that, we simulate a 5 percent shift, assuming disposable reserves at 5 percent of GDP (Figure 11). Growing total demand increases imports and current account deficit. As a result, reserves decrease for nine years to the extent such that the exchange rate needs to devalue by about 2 percent. Demand rebalances and external equilibrium restores at a permanently higher level of investment and interest rate, and lower consumption.

\footnotetext{
${ }^{20} \mathrm{We}$ admit that the model does not model any SPL effect on the potential output. In principle, there could be long-run effects stemming from capital accumulation or changes in total factor productivity. However, studying these effects requires different type of model and falls beyond the scope of our research.
} 
Figure 11: Impulse responses to 5 percent SPL shift (FX reserves $=5$ percent of GDP)
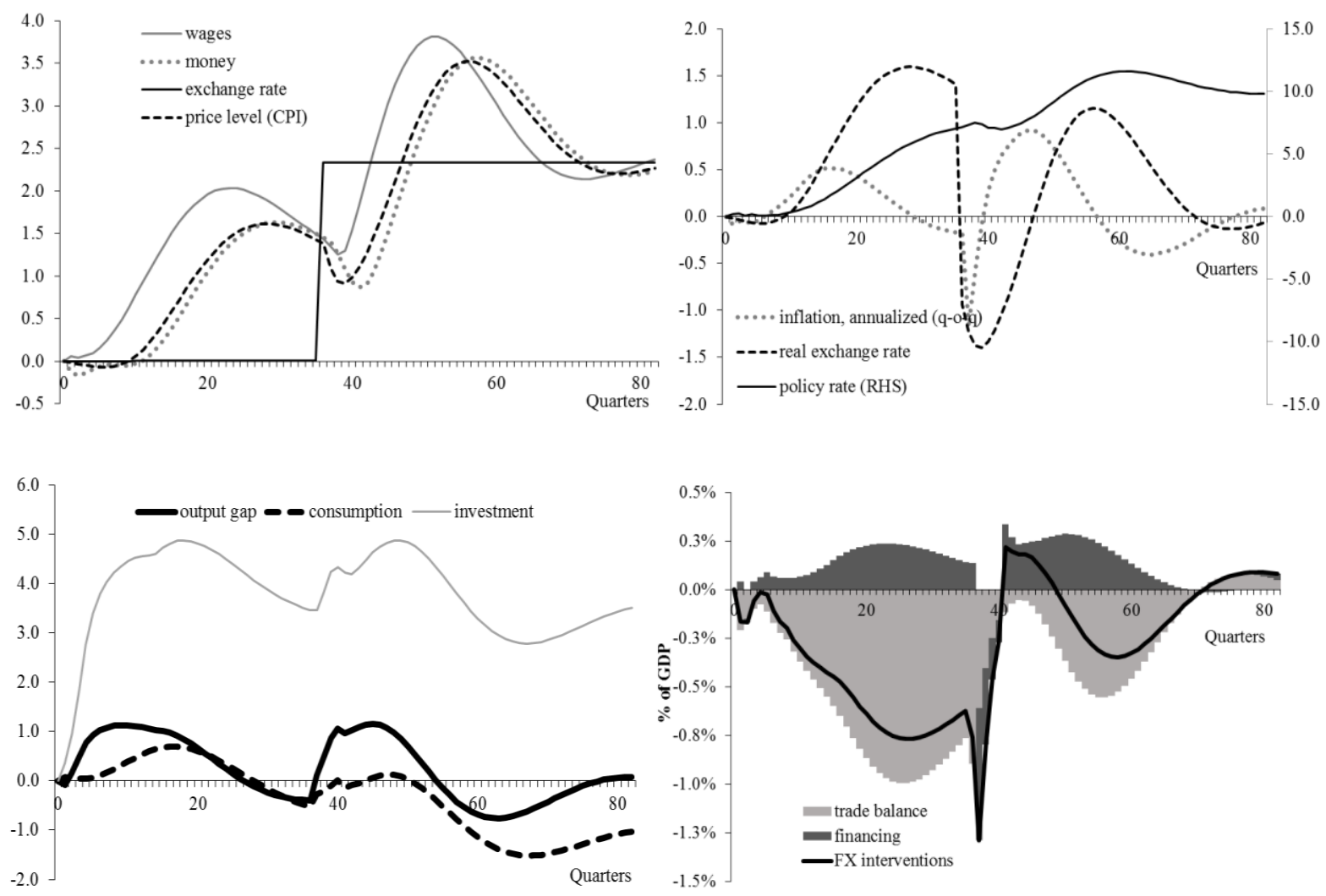

\section{Policy Discussion AND CONClusion}

We investigated the consequences of two important elements - activist wage policy and state program lending - for broader macroeconomic stability and sustainability of the monetary policy strategy prevailing in Belarus during 2001-2014.

First, we showed that a relatively mild positive shock to wages suppresses price competitiveness and stimulates current account deficits. Highly persistent real wages prolong the period of imbalances. Ultimately, foreign reserves diminish to an intolerable threshold in about 4 years and the NBRB has to realign (i.e., devalue) the nominal exchange rate to facilitate economic adjustment.

Second, similar dynamics are found in response to an increase in SPL. The NBRB sustains only small shocks, while larger changes lead to devaluation. In the longer run, consumption decreases permanently to accommodate higher investment. The interest rate for market loans permanently increases and limits access to non-subsidized domestic denominated credit. 
Third, a tighter interest rate is sufficient to avoid devaluation only if shocks to wages or SPL are small. Otherwise, the deteriorating current account exhausts foreign reserves before the elevated interest rates compresses demand to take economy back to equilibrium.

Although a weak interest rate channel is natural for a developing banking system, there were other forces at work to render it weak in Belarus. Although imperfect capital mobility allowed for some monetary autonomy, the efficiency of the interest rate instrument was limited by the rigid nominal exchange rate. The interest rate differential stimulated foreign capital flows and perceived stability of the nominal exchange rate suppressing FX risk perception, which incentivised borrowers to switch from domestic to foreign currency.

More importantly, there were structural reasons for a weak domestic interest rate channel. Structural weaknesses of the financial system often underlie weak interest rate channel in low-income and developing countries for various reasons (Mishra et al., 2010, 2012, 2014). In the specific case of Belarus the major factor behind it was likely to be the SPLs. Stateowned enterprises dominating the economy were subject to government production targets, and were provided extensive state support, including the SPL. Under such lending banks had little autonomy in deciding conditions and allocation of loans. The pass-through of the money market rate to longer-term rates was limited due to inelastic rates for SPL. Further, the activist wage policy and SPLs were pushing the market interest rates up via two mechanisms. First, large state-owned banks likely added premia to rates charged on market (i.e., non-subsidized) loans to offset liquidity and profitability pressures as they financed subsidized SPL. Second, both quasi-fiscal policies were keeping inflation high, which was prompting the NBRB and banks to keep the rubel market interest rates high. The elevated interest rates limited the flow of credit at market rates and the reach of the interest rate channel.

Overall, government quasi-fiscal objectives contradicted the established monetary policy strategy: positive increases to wages or SPL undermined the nominal exchange rate anchor. Monetary policy did not have enough buffers (reserves) and was too limited in its reach via the interest rate channel to offset the shocks and ensure macroeconomic stability. We can see this case if the government puts in place its own rigid (due to wage targets) "new nominal anchor". 
The activist wage policy dominates monetary policy and the exchange rate adjusts through the mechanism of a currency crisis to a new nominal level anchored by nominal wages. ${ }^{21}$

Another way of looking at the issue is the monetary-fiscal strategic game as described in Nordhaus (1994). The government undertakes (quasi-) fiscal expansion via expanding SPLs and directing state enterprises to increase wages. The game may potentially end in Nash equilibrium where the central bank reaches his exchange rate objective (and wins) at a cost of a high interest rate, while government is not able to reach economic objectives inconsistent with the long-run equilibrium, and (quasi-) fiscal expansion is not effective despite a high deficit.

In our case, however, the central bank does not have a strong enough interest rate instrument to win the game. All it largely has is interventions, limited due to small foreign reserves. The central bank is therefore destined to lose this game with undesired consequences for the exchange rate and macroeconomic stability.

A number of important conclusions for monetary and broader economic policy follow. Clearly, there must be only one nominal anchor in the economy, other nominal variables being endogenously determined. The power to decide the level of the nominal anchor has to remain with a central bank capable to defend the anchor.

Making the central bank capable involves rethinking the NBRB policy strategy and approaches to broader economic policy. Since fixed exchange rate regime does not appear viable in current conditions of low foreign reserves and weak alternative adjustment mechanisms (incl., due to wage and labour market rigidities), it would be useful for the NBRB to change its policy focus from the exchange rate to inflation. In fact, the low degree of international capital mobility in Belarus leaves room for the NBRB to migrate to the intermediate policy strategy of two objectives and two instruments, with a focus on the inflation target and a more flexible exchange rate smoothed via fully sterilized interventions (Ostry et al., 2012). Such a change of regime would require monetary policy to be more

\footnotetext{
${ }^{21}$ Besides, this may have important consequences for inflation expectations. Although fixed exchange rate is intended to stabilize expectations, rational agents would account for wage targets and allow for devaluations (the so called "peso problem"). This contributes to the instability of the monetary policy regime via elevated inflation expectations.
} 
forward-looking and decisive in its reaction to shocks. The new regime would allow for smoother adjustment of external imbalance and lower chances for crisis-like realignments. In a longer-run, a recurring sense of FX risk being present could help reorienting unhedged households and corporates to borrowing in domestic currency and, therefore, strengthening the interest rate channel. However, possibilities of the NBRB to stabilize economy will depend on consistency of the Government economic policy.

Changes in the monetary policy framework will not ensure broad and lasting macroeconomic stability as long as quasi-fiscal wage and SPL policies remain active. Discontinuing the wage policy and allowing wages to adjust according to a usual market mechanism would help on several fronts: namely, by eliminating the contradiction of anchors, stabilizing expectations and removing the source of ultimate currency crises. Flexible wages would turn from a source of imbalances to a shock absorber. Reduction in the SPL would have a similar effect. Additionally, the extent of redistribution and creating a two-fold economy - with one part entitled to subsidized loans and the other made to internalize losses via higher inflation and cost of market loans - would then be duly limited. This would also remove key structural weaknesses in the banking system and strengthen monetary policy transmission channels. Lastly, inflation would moderate and give way to a lower long-term level of interest rates, better access to the domestic currency denominated credit and, again, stronger interest rate channel. Ultimately, the NBRB would be better placed for conducting independent monetary policy and stabilizing economy.

It is worth noting that recent changes in macroeconomic policy are in line with our recommendation. Since 2014, government adopts annual SPL financing plans with the aim to reduce SPL. In 2015, the NBRB switched to monetary targeting and managed floating exchange rate. These steps are welcome changes. 


\section{REFERENCES}

Bernanke, B. and I. Mihov (1998): "Measuring monetary policy," Quarterly Journal of Economics CXIII, 315-34.

Branson, W. and D. Henderson (1985): "The Specification and Influence of Asset Markets", Handbook of International Economics, vol. 2, 749-805.

Eichenbaum, M. (1992): Comments on "Interpreting the Macroeconomic Time Series Facts: the Effects of Monetary Policy.” European Economic Review, 36(5), 1001-11.

Engle, R., D. Hendry and J.-F. Richard (1983): “Exogeneity”, Econometrica, 51, 277-304.

Flood, R. and P. Garber (1984): "Collapsing Exchange Rate Regimes: Some Linear Examples", Journal of International Economics, 17, 1-13.

Garratt, A., K. Lee, M.H. Pesaran and Y. Shin (2006): Global and National Macroeconometric Modelling: A Long Run Structural Approach, Oxford University Press, Oxford.

Horvath, B. and R. Maino (2006): "Monetary Transmission Mechanisms in Belarus", IMF Working Paper, 06/246.

IMF (2015): Republic of Belarus: Country Report 15/136.

Kallaur, P., V. Komkov and V. Chernookiy (2005): "Monetary Policy Transmission Mechanism in the Economy of the Republic of Belarus" (in Russian), Belarusian Economic Journal, 3, 4-15.

Koczan, Z. (2014): "Wage Dynamics in Belarus", IMF Country Report - Selected Issues, $14 / 227$.

Komkov, V., M. Demidenko and I. Beliatskiy (2008): "Inflationary Consequences of Price Increase for Imported Resources" (in Russian), Bankovskiy vestnik, 28, 5-11.

Krugman, P. (1979): “A Model of Balance-of-Payments Crises”, Journal of Money, Credit and Banking, 11, 311-325.

Kruk, D. and K. Haiduk (2013): "The Outcome of Directed Lending in Belarus: Mitigating Recession or Dampening Long-Run Growth?”, EERC Working Paper, 13/05.

Lucas, R. (1976): "Econometric Policy Evaluation: A Critique", Carnegie-Rochester Conference Series on Public Policy, 1, 19-46.

Miksjuk, A. and M. Pranovich (2007): "VECM and Analysis of the Rubel Interbank Credit Market in Belarus" (in Russian), Bankovskiy vestnik, 34, 19-27. 
Mishra, P., P.Montiel and A.Spilimbergo (2010): "Monetary Transmission in Low Income Countries", IMF Working Paper 10/223.

Mishra, P. and P. Montiel (2012): "How Effective Is Monetary Transmission in Low-Income Countries? A Survey of the Empirical Evidence", IMF Working Paper 12/143.

Mishra, P., P. Montiel, P. Pedroni and A.Spilimbergo (2014): "Monetary Policy and Bank Lending Rates in Low-Income Countries: Heterogeneous Panel Estimates", Journal of Development Economics 111, 117-131.

Nordhaus, W. (1994): "Policy Games: Coordination and Independence in Monetary and Fiscal Policies", Brookings Papers on Economic Activity, 2, 139-216.

Ostry, J., Ghosh, A. and M. Chamon (2012): "Two Targets, Two Instruments: Monetary and Exchange Rate Policies in Emerging Market Economies," IMF Staff Discussion Note, $12 / 01$.

Sims, C., (1992): "Interpreting the Macroeconomic Time Series Facts: the Effects of Monetary Policy,” European Economic Review, 36(5), 975-1000.

Stock, J.H. and M. W. Watson (2001): "Vector Autoregressions," Journal of Economic Perspectives, 15(4) 101-15. 


\section{APPENDIX I. LONG-RUN EQUILIBRIUM RELATIONSHIPS}

We define our long-run relationships by working with equilibrium or arbitrage conditions that are expected to prevail in the market ${ }^{22}$. The alternative approach would be to use some form of utility function, solve the inter-temporal optimization problem for a representative agent, impose log-linear approximation for the obtained relationships and assume that the economy is stationary and ergodic in the long run. As noted by Garrett et al. (2006), these two approaches lead to similar results for the long run properties of the model, but differ for the short run dynamics.

We assume that technological progress domestically and abroad follow the same long-run path, though commodities price fluctuations may also prove important given the difference in economies' structure. Home per capita output is homogeneous with respect to foreign output ${ }^{23}$ :

$$
\left(y_{t}-y_{t}^{*}\right)-\left(e m p l_{t}-e m p l_{t}^{*}\right)-\alpha_{0}-\alpha_{1}\left(p_{t}^{c o m}-p_{t}^{*}\right)=\varepsilon_{t}^{y},
$$

where $y_{t}$ and $y_{t}{ }^{*}$ are levels of output, empl $l_{t}$ and empl ${ }_{t}{ }^{*}$ are levels of employment, $p_{t}^{\text {com }}$ is commodities prices, $p_{t}{ }^{*}$ is foreign prices.

Both domestic and foreign prices are set with constant mark-up to nominal marginal costs (labour, energy and non-energy import costs). Then, relative prices depend on relative costs, allowing for Harrod-Balassa-Samuelson effect:

$$
\begin{aligned}
& q_{t}-\alpha_{2}-\alpha_{3}\left[\left(w_{t}-\left(y_{t}-e m p l_{t}\right)\right)-\left(s_{t}+w_{t}^{*}-\left(y_{t}^{*}-e m p l_{t}^{*}\right)\right)\right] \\
& -\alpha_{4}\left[p_{t}^{e n}-p_{t}^{e n^{*}}\right]-\left(1-\alpha_{3}-\alpha_{4}\right)\left[p_{t}^{i m}-p_{t}^{i m^{*}}\right]=\varepsilon_{t}^{q},
\end{aligned}
$$

where $q_{t}$ is real exchange rate, $w_{t}$ and $w_{t}{ }^{*}$ are nominal wages, $p_{t}^{e n}$ and $p_{t}^{e n^{*}}$ are energy import prices, $p_{t}^{i m}$ and $p_{t}^{i m^{*}}$ are non-energy import prices, $s_{t}$ is the nominal exchange rate.

We assume the standard exchange equation holds:

\footnotetext{
${ }^{22}$ Detailed derivation of the theoretical model may be found in the supplementary appendix at: http://www.jvi.org/about/staff-list/staff-detailview/member/mikhail-pranovich.html

${ }^{23}$ From here on, “*” indicate foreign variables and all lower-case variables are in natural logs.
} 
$m_{t}=p_{t}+y_{t}-v_{t}^{h p}+\varepsilon_{t}^{v}$

where $m_{t}$ is money stock, $v_{t}^{h p}$ is money velocity trend.

FX market equilibrium is defined by the balance of payments identity:

$\operatorname{Int}_{t} \equiv-\left[\left(P_{t}^{e x} \cdot C_{t}^{e x}-P_{t}^{i m} \cdot C_{t}^{i m}\right)+T B_{t}^{e n}+\operatorname{Transf}_{t}^{p r}\right]-\left[\mathrm{Fdi}_{t}^{p r}+\Delta N f l_{t}\right]$

where $I n t_{\mathrm{t}}$ is central bank FX interventions vis-à-vis the private sector (net sales of foreign assets), $P_{t}^{e x}, P_{t}^{i m}, C_{t}^{e x}, C_{t}^{i m}$ are export and import prices and volumes defining noncommodities trade balance, $T B_{t}^{e n}$ is the commodities trade balance (assumed exogenous), $N F L_{\mathrm{t}}$ is net foreign liabilities of the private sector, Transf $f_{t}^{p r}$ and $F d i_{t}^{p r}$ are the remaining current-account and financial-account operations of the private sector that we assume exogenous.

Given solvency constraint, one-sided interventions are not sustainable in the long-run:

$$
\operatorname{Int}_{t}=0+\varepsilon_{t}^{\mathrm{int}}
$$

Output growth and deviations from the UIP drive equilibrium private net foreign liabilities:

$n f l_{t}=\left(p_{t}+y_{t}-s_{t}\right)+b_{4}+b_{5}\left[\ln \left(1+N R_{t}\right)-\ln \left(1+N R_{t}^{f}\right)-E_{t} \Delta s_{t+1}\right]+\varepsilon_{t}^{n f l}$

where $N R_{t}$ and $N R_{t}^{f}$ are domestic and foreign interest rates, $E_{t}$ is the expectations operator.

Under different circumstances, alternative components of the BOP identity (A4) may prove important for the FX market. Foreign trade flows played major role in early $20^{\text {th }}$ century. The UIP is considered as an equilibrium condition in advanced economies, since capital flows liberalization in 1960s. In emerging economies like Belarus, capital flows mobility may de facto be constrained, limiting the importance of the UIP. Thus, we account for both, foreign trade and financial flows in our model. To treat the trade flows, we add all GDP expenditure components to the model. In volumes:

$$
\begin{aligned}
& \Delta y_{t} \equiv \alpha^{d e m} \Delta c_{t}+\left[\alpha^{e x} \Delta c_{t}^{e x}+\alpha^{e n_{-} x} \Delta x_{t}^{e n}\right]-\left[\alpha^{i m} \Delta c_{t}^{i m}+\alpha^{e n-m} \Delta m_{t}^{e n}\right] \\
& C_{t} \equiv \operatorname{Inv}_{t}+\operatorname{Cons}_{t}^{p r}+\operatorname{Cons}_{t}^{p u b}
\end{aligned}
$$




$$
\begin{aligned}
& c_{t}^{e x}=c_{t}^{*}-\lambda_{11} q_{t}+\lambda_{12}+\varepsilon_{t}^{c e x}, \\
& c_{t}^{i m}=c_{t}+\lambda_{13} q_{t}+\lambda_{14}+\varepsilon_{t}^{c i m}, \\
& \operatorname{inv}_{t}=y_{t}+\lambda_{0}-\lambda_{1}\left[p_{t}^{i n v}-p_{t}^{y}\right]-\lambda_{2} R_{t}-\lambda_{3} R_{t}^{f}+\lambda_{10} i n v_{t}^{G o v}+\varepsilon_{t}^{i n v}, \\
& \text { cons }_{t}^{p r}=e m p l_{t}+\left(w_{t}-p_{t}\right)+\lambda_{4}+\left(1-\lambda_{5}\right)\left[p_{t}-p_{t}^{y}\right]-\lambda_{6} R_{t}-\lambda_{7} R_{t}^{f}+\varepsilon_{t}^{c o n s}, \\
& \text { cons }_{t}^{p u}=\lambda_{8}+\lambda_{9} e m p l_{t}+\varepsilon_{t}^{c p u} .
\end{aligned}
$$

Respective prices:

$$
\begin{aligned}
& \Delta p_{t}^{y} \equiv \alpha^{c o n s} \Delta p_{t}+\alpha^{i n v} \Delta p_{t}^{i n v}+\alpha^{c p u} \Delta p_{t}^{p u}+\left[\alpha^{e x}\left(\Delta p_{t}^{e x}+\Delta s_{t}\right)+\alpha^{e n_{-} x}\left(\Delta p_{t}^{X}+\Delta s_{t}\right)\right]-\left[\alpha^{i m}\left(\Delta p_{t}^{i m}+\Delta s_{t}\right)+\alpha^{e n \_}{ }^{m}\left(\Delta p_{t}^{M}+\Delta s_{t}\right)\right] \\
& p_{t}^{i n v}=\lambda_{19}+\lambda_{20} p_{t}^{y}+\left(1-\lambda_{20}\right)\left[p_{t}^{i m}+s_{t}\right]+\varepsilon_{t}^{p i n v} \\
& p_{t}^{p u}=\lambda_{21}+\lambda_{22} p_{t}+\left(1-\lambda_{22}\right) w_{t}+\varepsilon_{t}^{p p u} \\
& p_{t}^{e x}=\lambda_{15}+\lambda_{16} p_{t}^{*}+\left(1-\lambda_{16}\right)\left[p_{t}-s_{t}\right]+\varepsilon_{t}^{p e x}, \\
& p_{t}^{i m}=\lambda_{17}+\lambda_{18} p_{t}^{*}+\left(1-\lambda_{18}\right)\left[p_{t}-s_{t}\right]+\varepsilon_{t}^{p i m},
\end{aligned}
$$

where $\operatorname{cons}_{t}^{p u}, i n v_{t}, x_{t}^{e n}, m_{t}^{e n}$ are real public consumption, investment, commodities export and import, $p_{t}^{p u}, p_{t}^{i n v}, p_{t}^{X}, p_{t}^{M}$ are the corresponding deflators, cons $s_{t}^{p r}$ is real private consumption, $c_{t}$ is absorption, $p_{t}^{y}$ is GDP deflator, $p_{t}{ }^{*}$ are foreign prices, $R_{t}$ and $R_{t}^{f}$ are real interest rate in domestic and in foreign currency.

To analyse the central bank tools, we model the money multiplier and the interest rate spread:

$$
\begin{aligned}
& m_{t}-b_{t}=-\lambda_{25} r e q_{t}-\lambda_{26} R_{t}+\lambda_{27} R_{t}^{i b}+\lambda_{28}\left[b_{t}-p_{t}\right]-\lambda_{29} \Delta p_{t}+\varepsilon_{t}^{b} \\
& \left(R_{t}-R_{t}^{i b}\right)-\lambda_{23}+\lambda_{24}\left(m_{t}-b_{t}\right)=\varepsilon_{t}^{s p r}
\end{aligned}
$$

where $r e q_{t}$ is the required reserves ratio. 
We treat employment $\left(e m p l_{\mathrm{t}}\right)$ as exogenous, implicitly assuming that supply of labor is inelastic and demographic factors, namely, a fraction of the working-age population drives equilibrium employment.

Variables $\varepsilon^{X}$ in (A1)-(A20) are the so called long-run reduced-form disturbances, which represent some linear combinations of long-run structural disturbances (Garrett et al., 2006). ${ }^{24}$ Variable $v_{\mathrm{t}}^{\mathrm{hp}}$ is the long-term trend of $v_{\mathrm{t}}$, which we estimate using Hodrick-Prescott filter.

To estimate the domestic output gap we use disturbance $\varepsilon^{\mathrm{y}}$ in (A1) and neglect technology and capital accumulations disturbances. Then:

$y_{t}-\bar{y}_{t} \approx \varepsilon_{t}^{\text {ygap }} \equiv \varepsilon_{t}^{y}+\left(y_{t}^{*}-\bar{y}_{t}^{*}\right)$,

where foreign output gap $\left(y_{t}^{*}-\bar{y}_{t}^{*}\right)$ is estimated using Hodrick-Prescott filter.

\section{APPENDIX II. DATA DESCRIPTION}

Table A1 presents variables, which we use in our model. Endogenous variables include most of domestic economic variables and policy instruments. A few domestic variables are treated as exogenous: employment (Empl $l_{t}$ driven by demographic factors not captured in the model), money velocity trend $\left(V_{t}^{h p}\right)$, required reserve ratio $\left(R e q_{t}\right.$, not considered it as an active policy instrument) and some balance of payments components $\left(T B_{t}^{e n}, X_{t}^{e n}, M_{t}^{e n}, P_{t}^{i m_{-} \text {oil }}\right.$, Transf $f_{t}^{p r}$, $F d i_{t}^{p r}$ ) largely determined by idiosyncratic shocks rather than economic factors. All foreign variables are exogenous.

Some additional clarification regarding the endogenous variables is necessary. We exclude energy products and potash to get foreign trade volumes $\left(C_{t}^{e x}, C_{t}^{i m}\right)$ and prices $\left(P_{t}^{e x}, P_{t}^{i m}\right)$. We consider the former as exogenously determined in the world commodity market (Belarus has significant stocks of potash and large oil refinery sector: oil, oil products, gas and potash constitute $1 / 3$ of Belarusian foreign trade in goods). We exclude foreign borrowing that is directly linked to domestic operations vis-à-vis the Government or the central bank from private sector foreign liabilities $\left(N f l_{t}\right)$ and foreign exchange interventions $\left(\right.$ Int $\left.y_{t}\right)$. Such specific private sector borrowing is not driven by economic factors (i.e., interest rate

\footnotetext{
${ }^{24}$ For example, the reduced form disturbance in (1): $\varepsilon^{\mathrm{y}}=\eta_{\alpha \mathrm{t}}+\eta_{\mathrm{kt}}+\mu_{\mathrm{yt}}+\mu_{\mathrm{yt}}$
} 
differential). Rather, it de facto represents indirect foreign borrowing of authorities and is subject to their policy decisions. We approximate real effective exchange rate $\left(Q_{t}\right)$ with a weighted average of bilateral real exchange rates for two major trading partners: Russia and Eurozone.

Data on directed lending is available only since 2006, however, and of poor quality at least until 2009. Disbursement of long-term loans at market conditions is rather limited in Belarus, and directed lending drives most of the changes in their stock. Thus, we use data on all longterm banking loans $\left(\operatorname{Inv}{ }_{t}^{G o v}\right)$ to approximate directed lending: in interpreting the results we still refer to this variable as directed lending. Lastly, interest rates $N R_{t}, R_{t}$ are net of directed lending rates.

In the production function we use world GDP $\left(Y_{t}^{\text {world }}\right)$ as the foreign output that drives technology and capital accumulation, world population $\left(\right.$ Pop $\left._{t}{ }^{\text {world }}\right)$ is a proxy for world employment, and Brent oil prices $\left(P_{t}^{\text {brent }}\right.$ ) is the sources of technology divergence (given large share of oil refinery sector in Belarus). Demand for exports is approximated with a combination of volumes of Russian industrial production $\left(\operatorname{Ind}_{t}^{\text {rus }}\right)$, EU industrial production $\left(\operatorname{Ind}_{t}^{e u}\right)$ and world GDP $\left(Y_{t}^{\text {world }}\right)$ with the weights of 2/3, 1/6 and 1/6 respectively. These weights largely correspond to directions of trade in non-energy and non-potash exports. Similarly, export and import prices are approximated with Russian and EU industrial prices $\left(P_{t}^{r u s_{-} i}, P_{t}^{e{ }_{-} i}\right)$ and the rest-of-the-world prices for tradable goods (approximated with US apparel prices $\left.P_{t}^{u s_{-} a p p a r e l}\right)$. Finally, in equation (2) we use Russian output $\left(Y_{t}^{r u s}\right)$, employment $\left(E m p l_{t}^{r u s}\right)$ and wages $\left(W_{t}^{r u s}\right)$ to capture Harrod-Balassa-Samuelson effect, and imported oil prices relative to Brent prices $\left(P_{t}^{i m_{-} \text {oil }} / P_{t}^{\text {brent }}\right)$ to capture energy shocks.

Table A1. Data description ${ }^{1,2}$

\begin{tabular}{l|l}
\hline Variable & \multicolumn{1}{c}{ Description } \\
\hline \multicolumn{3}{|c|}{ Endogenous variables } \\
$Y_{t}$ & GDP, in 2000 prices \\
$\operatorname{lnv}_{t}$ & Domestic investment, in 2000 prices \\
Cons $_{t}^{p r}$ & Household consumption expenditure, in 2000 prices \\
Cons $_{t}^{p u}$ & Government consumption expenditure, in 2000 prices \\
$C_{t}$ & Domestic demand $C_{t}=\operatorname{Inv}_{t}+$ Cons $_{t}^{p r}+$ Cons $_{t}^{p u}$, in 2000 prices \\
$C_{t}^{e x}$ & Non-energy and non-potash exports volume, $2001 \mathrm{Q} 1=1$
\end{tabular}


$C_{t}^{\prime m} \quad$ Non-energy imports volume, 2001Q1=1

$P_{t}^{y} \quad$ GDP deflator: value of GDP in current prices over $Y_{t}$

$P_{t}^{I n v} \quad$ Investments deflator: investment value in current prices over $\ln v_{t}$

$P_{t} \quad$ Consumer price index ${ }^{3}$, Jan-2001 $=1$

$P_{t}^{p u} \quad$ Public consumption deflator: public consumption value in current prices over Cons ${ }_{t}^{p u}$

$P_{t}^{e x} \quad$ Prices of non-energy and non-potash exports, US dollar index, 2001Q1=1

$P_{t}^{\prime m} \quad$ Prices of non-energy imports, US dollar index, 2001Q1=1

$Q_{t}^{\text {rus }} \quad$ Real exchange rate of Belarusian rubel against Russian rubel (domestic to foreign prices), $2005=1$

$Q_{t} \quad$ Real effective exchange rate index (domestic to foreign prices), 2005=1: $Q_{\mathrm{t}}=Q_{\mathrm{t}}^{\text {rus }} \cdot\left[Q_{\mathrm{t}}^{\text {eu_rus }}\right]^{1 / 3}$, where $Q_{t}^{\text {eu } \_ \text {rus }}$ is bilateral real exchange rates of euro against Russian rubel

$S_{t}^{\text {usa }} \quad$ Nominal exchange rate of Belarusian rubel against US dollar, BLR per 1 USD

$S_{t}^{\text {eur }} \quad$ Nominal exchange rate of Belarusian rubel against Euro, BLR per 1 EUR

$S_{t}^{\text {rub }} \quad$ Nominal exchange rate of Belarusian rubel against Russian rubel, BLR per 1 RUB

$\mathrm{Nf}_{t} \quad$ Net foreign debt liabilities of the private sector excl. liabilities related to domestic operations vis-à-vis the Government or the central bank, in USD

$N R_{t} \quad$ Average nominal interest rates on domestic currency banking loans to the economy, \% per annum

$N R_{t}^{10} \quad$ Average nominal interest rates for interbank loans in domestic currency, \% per annum

$R_{t} \quad$ Real interest rate on domestic currency banking loans to the economy, ${ }^{4} \%$ per annum: $R_{\mathrm{t}}=\left(1+N R_{\mathrm{t}}\right) /\left(1+P_{\mathrm{t}} / P_{\mathrm{t}-4}\right)-1$

$R_{t}^{\text {ID }} \quad$ Real interest rate on domestic currency interbank loans, ${ }^{4} \%$ per annum: $R_{\mathrm{t}}^{\mathrm{ib}}=\left(1+N R_{\mathrm{t}}^{\mathrm{ib}}\right) /\left(1+P_{\mathrm{t}} / P_{\mathrm{t}-4}\right)-1$

$W_{t} \quad$ Average nominal wages, in rubels

$M_{t} \quad$ Domestic currency money $\mathrm{M} 2$, in rubels

$B_{t} \quad$ Domestic currency reserve money (monetary base), in rubels

Inty $y_{t} \quad$ NBRB's interventions (net purchase of foreign currency) excl. operations with banks directly linked to banks' foreign borrowing, \% to GDP

$\ln v_{t}^{\text {ciov }} \quad$ Long-term banking loans disbursment to the economy, relative to GDP

$V_{t} \quad$ Velocity of M2: $V_{t}=P_{t} Y_{t} / M_{t}$

\section{Exogenous variables}

Empl $I_{t} \quad$ Employment, number of people employed

$V_{t}^{\text {np }} \quad$ Trend of the M2 velocity, estimated using Hodrick-Prescott filter

$R e q_{t} \quad$ Average required reserve ratio: stock of required reserves over the stock of all deposits (in home and foreign prices)

$R_{t}^{t} \quad$ Real interest rate on foreign denominated banking loans, \% per annum: $\mathrm{R}_{\mathrm{t}}{ }^{t}=\left(1+\mathrm{NR}_{\mathrm{t}}\right)^{*}\left(1+\left[\mathrm{s}_{\mathrm{t}}{ }^{\text {usa }}-\right.\right.$ $\left.\left.\mathrm{s}_{\mathrm{t}-4}{ }^{\mathrm{usd}}\right]\right) /\left(1+\left[\mathrm{p}_{\mathrm{t}}-\mathrm{p}_{\mathrm{t}-4}\right]\right)-1,{ }^{4}$

$N R_{t}^{t} \quad$ Average nominal interest rates on foreign denominated banking loans, \% per annum

$\mathrm{TB}_{t}^{\text {en }} \quad$ Energy-and-potash trade balance, in USD

$X_{t}^{e n} \quad$ Volume of energy-and-potash exports calculated using data on volumes and values of oil products, oil and potash exports, weighted average of commodities

$M_{t}^{e n} \quad$ Volume of energy imports, weighted average of energy commodities 


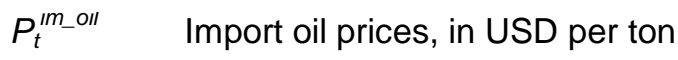

Transf $_{t}^{\text {pr }} \quad$ Net private sector income inflow, including investment income (net of Government percentage payments on foreign debt), labour income and remittances, in USD

$\mathrm{Fdi}_{t}^{\text {pr }} \quad$ Net FDI inflow excl. privatization, in USD

$Y_{t}^{\text {worla }} \quad$ Trend of world real GDP calculated using linear interpolation of IMF's annual data, 2000Q4=1

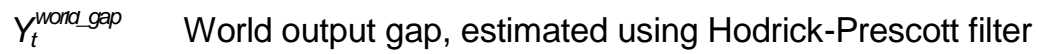

$Y_{t}^{\text {rus }} \quad$ GDP in Russia, in 2008 prices

Ind $_{t}^{\text {rus }} \quad$ Industrial production index in Russia, Jan-2004=1

$\operatorname{Ind}_{t}^{\text {eu }} \quad$ Industrial production index in EU-27, 2001Q1=1

Pop $_{t}^{\text {worl }}$ Trend of world population calculated using linear interpolation of UN's 5-year estimates, number of people

$E m p l_{t}^{\text {rus }} \quad$ Employment in Russia, number of employed

$W_{t}^{\text {rus }} \quad$ Average nominal wages in Russia, in RUB

$P_{t}^{\text {brent }} \quad$ Brent oil price, USD per barrel

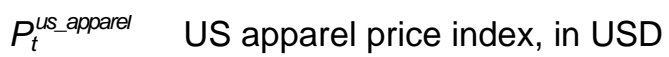

$P_{t}^{\text {ns }} \quad$ Consumer price index in Russia, ${ }^{3}$ Jan-2001 $=1$

$P_{t}^{e u} \quad$ Consumer price index in EU-27, ${ }^{3}$ Jan-2001 = 1

$P_{t}^{\prime m} \quad$ Import prices in Russia, 2002Q1=1

$P_{t}^{\text {rus } \_} \quad$ Producer price index in Russia, ${ }^{3}$ Dec-2001=1

$P_{t}^{e u}{ }_{-1} \quad$ Producer price index in EU-27 (domestic market), ${ }^{3}$ Jan-2001=1

Note: ' - variables are seasonally adjusted when necessary; ${ }^{2}-$ in whąt follows, lower-case variables denote natural logarithms of the corresponding upper-case variables; ${ }^{3}$ - converted from monthly to quarterly frequency; ${ }^{4}$ - we set real interest rates to zero during and 1 year after currency crises (2009, 2011q2-2012q3), as we are unable to capture inflation and devaluation expectations at that period.

\section{APPENDIX III. UnIT RoOT TEST RESUlTS}

The results of augmented Dickey-Fuller test are provided in Table A2. We use visual analysis to specify deterministic components in the test (linear trend was included in most test specifications) and select the lag length based on Schwarz information criterion.

Most of the variables are found to be integrated of order 1 (denoted $I(1)$ ) at $5 \%$ significance level. Foreign reserves to GDP ratio $\left(\right.$ Inty $\left._{t}\right)$ and reserve requirements $\left(\mathrm{req}_{t}\right)$ are stationary. World output gap $Y_{t}^{\text {world_gap }}$ is stationary by definition. There is some ambiguity regarding nominal exchange rate $\left(s_{t}{ }^{r u b}\right)$, which we assume to be $I(1)$ given that other nominal exchange rates are $I(1)$. It is not clear whether nominal interest rate $N R_{t}$ is $I(1)$ or $I(2)$ and whether nominal interest rate $N R_{t}^{i b}$ is $I(0)$ or $I(1)$. We assume the interest rates to be homogeneous and so to have the same order of integration, $I(1)$.

Test results for world output $\left(y_{t}^{\text {world }}\right)$, Russian output $\left(y_{t}^{\text {rus }}\right)$ and Russian wages $\left(w_{t}^{\text {rus }}\right)$ are counter-intuitive, as we do not expect the variables to be $I(2)$. The results change when more 
lags are introduced in test specification (Table A3). Thus, we assume $y_{t}^{\text {world }}, y_{t}^{\text {rus }}, w_{t}^{\text {rus }}$ to be $I(1)$.

Two time series seem to have a structural break. For Belarusian public consumption ( cons $_{t}^{p u}$ ) there may be a sequence of breaks in 2011-2014, as the authorities were seeking to optimize the number of public servants. These breaks are difficult to account for, so we truncated the test period up to III quarter 2011. In this case ADF test indicates $\operatorname{cons}_{t}^{p u}$ to be stationary.

For the directed lending ( inv $_{t}^{\text {Gov }}$ ) there could be a change in trend in 2011, as a new central bank Governor took office. To account for the structural break we used Perron (1989) unit root test $\mathrm{t}^{25}$ (Table A4). Test results indicate $i n v_{t}^{\text {Gov }}$ be trend stationary at $10 \%$ level.

To sum up, we consider all the time series to be $I(1)$, except for $Y_{t}^{\text {worldsap }}$, Inty $_{t}$, req $_{t}$, inv ${ }_{t}^{\text {Gov }}$ and $\operatorname{cons}_{t}^{p u}$, which are found to be stationary.

Table A2. ADF test results

\begin{tabular}{|c|c|c|c|c|c|c|c|}
\hline & \multicolumn{3}{|c|}{ ADF tests for the levels } & \multicolumn{4}{|c|}{ ADF tests for the first differences } \\
\hline variable & test spec $\uparrow$ & t-statistics & p-value & variable & test spect & t-statistics & p-value \\
\hline$y_{t}$ & $\mathrm{~T}, 0$ & 0.14 & 1.00 & $\Delta y_{t}$ & $\mathrm{C}, 0$ & -7.15 & $0.00^{\star *}$ \\
\hline $\operatorname{inv} v_{t}$ & $\mathrm{~T}, 3$ & 0.33 & 1.00 & $\Delta i n v_{t}$ & C, 1 & -10.5 & $0.00^{* *}$ \\
\hline conss $_{t}^{\prime \prime}$ & $\mathrm{T}, 0$ & -2.56 & 0.30 & $\Delta \operatorname{cons}_{t}{ }^{\mu t}$ & C, 0 & -9.00 & $0.00^{* *}$ \\
\hline conss $_{t}^{\text {pu }}$ & C, 0 & -0.90 & 0.78 & $\Delta \operatorname{cons}_{t}^{\mu u}$ & $\mathrm{~N}, 0$ & -7.36 & $0.00^{* *}$ \\
\hline$c_{t}^{e x}$ & $\mathrm{~T}, 0$ & -2.34 & 0.41 & $\Delta c_{t}^{e x}$ & $\mathrm{C}, 0$ & -6.91 & $0.00^{\star *}$ \\
\hline$c_{t}^{\prime \prime \prime \prime}$ & $\mathrm{T}, 0$ & -3.22 & $0.09^{*}$ & $\Delta c_{t}^{\prime \prime \prime \prime}$ & C, 0 & -9.01 & $0.00^{* *}$ \\
\hline$p_{t}^{y}$ & $\mathrm{~T}, 2$ & -2.73 & 0.23 & $\Delta p_{t}^{y}$ & C, 2 & -3.16 & $0.03^{* *}$ \\
\hline$p_{t}^{\prime \prime \prime v}$ & $\mathrm{~T}, 0$ & -2.15 & 0.50 & $\Delta p_{t}^{\prime \prime I V}$ & C, 0 & -6.75 & $0.00^{\star *}$ \\
\hline$p_{t}$ & $\mathrm{~T}, 1$ & -2.37 & 0.39 & $\Delta p_{t}$ & C, 1 & -3.61 & $0.01^{\star *}$ \\
\hline$p_{t}^{\text {pu }}$ & $\mathrm{T}, 0$ & -1.46 & 0.83 & $\Delta p_{t}^{\text {pu }}$ & C, 0 & -6.53 & $0.00^{\star *}$ \\
\hline$p_{t}^{e x}$ & $\mathrm{~T}, 1$ & -1.67 & 0.35 & $\Delta p_{t}^{e x}$ & C, 1 & -5.05 & $0.00^{* *}$ \\
\hline$p_{t}^{\prime \prime \prime \prime}$ & $\mathrm{T}, 1$ & -2.56 & 0.30 & $\Delta p_{t}^{\prime \prime \prime \prime}$ & C, 1 & -5.27 & $0.00^{\star *}$ \\
\hline$q_{t}^{\text {ius }}$ & $\mathrm{T}, 1$ & -0.89 & 0.95 & $\Delta q_{t}^{\text {ius }}$ & C, 0 & -3.58 & $0.01^{* *}$ \\
\hline$q_{t}$ & $\mathrm{~T}, 1$ & -1.79 & 0.70 & $\Delta q_{t}$ & C, 0 & -4.69 & $0.00^{\star *}$ \\
\hline$s_{t}^{\text {usu }}$ & $\mathrm{T}, 1$ & -1.73 & 0.72 & $\Delta s_{t}^{\text {usu }}$ & C, 0 & -4.13 & $0.00^{\star *}$ \\
\hline$s_{t}^{\text {eur }}$ & $\mathrm{T}, 1$ & -2.09 & 0.54 & $\Delta \boldsymbol{s}_{t}^{\text {eur }}$ & C, 0 & -4.71 & $0.00^{\star *}$ \\
\hline$s_{t}^{\prime \text { un }}$ & $\mathrm{T}, 1$ & -2.46 & 0.34 & $\Delta s_{t}^{\prime \text { iv }}$ & C, 0 & -2.81 & $0.06^{*}$ \\
\hline$\left.n f\right|_{t}$ & $\mathrm{~T}, 0$ & -2.68 & 0.25 & $\left.\Delta n f\right|_{t}$ & C, 0 & -7.45 & $0.00^{* *}$ \\
\hline$N R_{t}$ & $\mathrm{~T}, 3$ & -2.49 & 0.33 & $\Delta N R_{t}$ & C, 2 & -2.75 & $0.07^{\star}$ \\
\hline$N R_{t}$ & C, 3 & -2.69 & $0.08^{*}$ & $\Delta N R_{t}$ & $\mathrm{~N}, 2$ & -2.68 & $0.01^{* *}$ \\
\hline$N R_{t}^{i v}$ & $\mathrm{~T}, 2$ & -3.24 & $0.09^{*}$ & $\Delta N R_{t}^{\prime \nu}$ & C, 1 & -7.88 & $0.00^{\star *}$ \\
\hline$N R_{t}^{i \nu}$ & C, 2 & -3.62 & $0.01^{* *}$ & $\Delta N R_{t}^{\prime \prime}$ & $\mathrm{N}, 1$ & -7.76 & $0.00^{\star *}$ \\
\hline$w_{t}$ & $\mathrm{~T}, 1$ & -2.34 & 0.40 & $\Delta w_{t}$ & C, 0 & -3.31 & $0.02^{* *}$ \\
\hline
\end{tabular}

\footnotetext{
${ }^{25}$ The ADF testing model is extended with dummies allowing for shift in intercept and change in the time trend. Perron's critical values are applied to test for unit root.
} 


\begin{tabular}{|c|c|c|c|c|c|c|c|}
\hline$m_{t}$ & $\mathrm{~T}, 1$ & -2.29 & 0.43 & $\Delta m_{t}$ & $\mathrm{C}, 0$ & -3.49 & $0.01^{* *}$ \\
\hline$b_{t}$ & $\mathrm{~T}, 1$ & -2.08 & 0.54 & $\Delta b_{t}$ & $\mathrm{C}, 0$ & -4.68 & $0.00^{* *}$ \\
\hline Inty $_{t}$ & $\mathrm{C}, 0$ & -4.67 & $0.00^{* *}$ & & & & \\
\hline$i n v_{t}^{\text {uuv }}$ & $\mathrm{T}, 0$ & -1.24 & 0.89 & $\Delta i n v_{t}^{\text {uuv }}$ & $\mathrm{C}, 0$ & -7.95 & $0.00^{* *}$ \\
\hline$e m p l_{t}$ & $\mathrm{~T}, 1$ & -0.65 & 0.97 & $\Delta e m p l_{t}$ & $\mathrm{C}, 0$ & -4.64 & $0.00^{* *}$ \\
\hline$r e q_{t}$ & C, 0 & -3.47 & $0.01^{* *}$ & & & & \\
\hline$N R_{t}^{\prime}$ & $\mathrm{T}, 1$ & -2.84 & 0.19 & $\Delta N R_{t}^{\prime}$ & C, 0 & -4.12 & $0.00^{\star *}$ \\
\hline$N R_{t}^{\prime}$ & C, 1 & -2.29 & 0.18 & $\Delta N R_{t}^{\prime}$ & $\mathrm{N}, 0$ & -4.09 & $0.00^{* *}$ \\
\hline$p_{t}^{\prime \prime \prime \prime}+u^{\prime \prime \prime}$ & $\mathrm{T}, 0$ & -1.68 & 0.38 & $\Delta p_{t}^{\prime \prime \prime \prime}-$ uाI & $\mathrm{C}, 0$ & -6.76 & $0.00^{* *}$ \\
\hline$y_{t}^{\text {wvoru }}$ & $\mathrm{T}, 1$ & -2.35 & 0.40 & $\Delta y_{t}^{\text {vuvilu }}$ & $\mathrm{C}, 0$ & -2.59 & 0.10 \\
\hline$y_{t}^{\prime \text { Ius }}$ & $\mathrm{T}, 2$ & -1.82 & 0.68 & $\Delta y_{t}^{\text {Ius }}$ & C, 1 & -2.45 & 0.13 \\
\hline$i n d_{t}^{\prime u s}$ & $\mathrm{~T}, 0$ & -1.77 & 0.71 & $\Delta i n d_{t}^{\prime \text { us }}$ & $\mathrm{C}, 0$ & -6.63 & $0.00^{* *}$ \\
\hline ind $_{t}^{\mathrm{eu}}$ & $\mathrm{T}, 1$ & -3.44 & $0.06^{*}$ & $\Delta i n d_{t}^{e u}$ & C, 1 & -4.06 & $0.00^{\star *}$ \\
\hline empl $\left.\right|_{t} ^{\prime \text { us }}$ & $\mathrm{T}, 0$ & -2.14 & 0.51 & $\Delta e m p l_{t}^{\prime \text { us }}$ & $\mathrm{C}, 0$ & -6.88 & $0.00^{* *}$ \\
\hline$w_{t}^{\prime u s}$ & $\mathrm{~T}, 3$ & -0.19 & 0.99 & $\Delta w_{t}^{\prime u s}$ & C, 1 & -2.38 & 0.15 \\
\hline$p_{t}^{\text {UIEII }}$ & $\mathrm{T}, 1$ & -2.51 & 0.32 & $\Delta p_{t}^{\text {vIEIII }}$ & C, 1 & -6.06 & $0.00^{* *}$ \\
\hline$p_{t}^{\text {us_anvarer }}$ & $\mathrm{T}, 1$ & -2.41 & 0.37 & $\Delta p_{t}^{\text {us_annaret }}$ & $\mathrm{C}, 0$ & -4.86 & $0.00^{* *}$ \\
\hline$p_{t}^{\text {Ius }}$ & $\mathrm{T}, 1$ & -1.56 & 0.79 & $\Delta p_{t}^{\text {ius }}$ & $\mathrm{C}, 0$ & -4.39 & $0.00^{* *}$ \\
\hline$p_{t}^{\text {eu }}$ & $\mathrm{T}, 1$ & -0.85 & 0.95 & $\Delta p_{t}^{\text {eu }}$ & $\mathrm{C}, 0$ & -4.92 & $0.00^{* *}$ \\
\hline$p_{t}^{\prime \prime \prime \prime}$ & $\mathrm{T}, 1$ & -1.67 & 0.75 & $\Delta p_{t}^{\prime \prime \prime \prime}$ & C, 0 & -6.18 & $0.00^{\star *}$ \\
\hline$p_{t}^{\prime \prime u \nu_{-}}$ & $\mathrm{T}, 1$ & -2.11 & 0.53 & $\Delta p_{t}^{\text {'us_t }}$ & C, 1 & -4.72 & $0.00^{* *}$ \\
\hline$p_{t}^{\text {eu_t }}$ & $\mathrm{T}, 1$ & -2.45 & 0.35 & $\Delta p_{t}^{\text {eu_t }}$ & C, 1 & -4.04 & $0.00^{* *}$ \\
\hline
\end{tabular}

Note: $\dagger$ - indicates deterministic components specification ( $\mathrm{T}$ - trend and intercept, $\mathrm{C}$ - intercept only, $\mathrm{N}$ - none) and the number of lags, ${ }^{* *}$ - indicates rejection of the null hypothesis of a unit root at $5 \%$ and ${ }^{*}$ - rejection at $10 \%$.

Table A3. ADF test results: alternative test specification

\begin{tabular}{|c|c|c|c|c|c|c|c|}
\hline \multicolumn{3}{|c|}{ ADF tests for the first differences } & \multicolumn{3}{c|}{ ADF tests for the first differences } \\
\hline Variable & $\begin{array}{c}\text { Test } \\
\text { spect }\end{array}$ & t-statistics & p-value & Variable & $\begin{array}{c}\text { Test } \\
\text { spect }\end{array}$ & t-statistics & p-value \\
\hline$\Delta y_{t}^{\text {world }}$ & $\mathrm{C}, 1$ & -2.71 & $0.08^{*}$ & $\Delta y_{t}^{\text {word }}$ & $\mathrm{C}, 2$ & -2.86 & $0.06^{*}$ \\
$\Delta y_{t}^{\text {rus }}$ & $\mathrm{C}, 2$ & -4.06 & $0.00^{* *}$ & $\Delta y_{t}^{\text {rus }}$ & $\mathrm{C}, 3$ & -2.81 & $0.06^{*}$ \\
$\Delta w_{t}^{\text {rus }}$ & $\mathrm{C}, 2$ & -2.74 & $0.07^{*}$ & $\Delta w_{t}^{\text {rus }}$ & $\mathrm{C}, 3$ & -1.80 & 0.38 \\
\hline
\end{tabular}

Note: $\dagger$ - indicates deterministic components specification ( $\mathrm{T}-$ trend and intercept, $\mathrm{C}$ - intercept only, $\mathrm{N}-$ none) and the number of lags, ${ }^{* *}$ - indicates rejection of the null hypothesis of a unit root at $5 \%$ and $*$ - rejection at $10 \%$.

Table A4. Perron test results

\begin{tabular}{|c|c|c|c|c|c|}
\hline Variable & Test spec $\dagger$ & Struct. break & t statistics & critical value 5\% & critical value 10\% \\
\hline inv $_{t}^{\text {Giov }}$ & $\mathrm{T}, 0$ & $2 \mathrm{q} 2011$ & -3.84 & -4.18 & -3.86 \\
\hline
\end{tabular}

$\dagger$ - Indicates structural break specification ( $T$ - trend and intercept, $\mathrm{C}$ - intercept) and the number of lags 


\section{ApPENDix IV. CoIntegration Test Results}

In the model (A4), (A7), (A8), (A14) are identities, (A3) holds by construction, equations (A5), (A13), (3) are in stationary variables, while (A1), (A2), (A6), (A9)-(A12), (A15)-(A20) are formulated for $I(1)$. To test the specification of the latter we use Engle-Granger test for cointegration. The results of the test are reported in Table A5.

In the test, we use MacKinnon p-values, which depend on the number of unrestricted parameters in the cointegrating relationship (cited first in the second column of Table A5). The other two parameters in the test specification include deterministic components (selected based on relationships (A1)-(A20) and (3)) and lag length (selected based on Schwarz information criterion).

Table A5. Engle-Granger test results

\begin{tabular}{|c|c|c|c|c|c|c|c|c|c|}
\hline Equation & Residual & Testspec† & tstatistics & pvalue & Equation & Residual & Test spec† & tstatistics & pvalue \\
\hline (A1) & $\varepsilon_{t}^{y}$ & 2: C, 0 & -3.24 & $0.08^{*}$ & (A15) & $\varepsilon_{t}^{\text {pinv }}$ & 2: C, 0 & -5.74 & $0.00^{\star \star}$ \\
\hline (A2) & $\varepsilon_{t}^{q}$ & 2: C, 0 & -3.23 & $0.08^{*}$ & (A16) & $\varepsilon_{\mathrm{t}}^{\mathrm{ppu}}$ & 2: C, 0 & -4.08 & $0.01^{* *}$ \\
\hline (A6) & $\varepsilon_{t}^{n+1}$ & 2: C, 0 & -2.54 & 0.27 & (A17) & $\varepsilon_{t}^{\text {pex }}$ & 2: C, 0 & -2.93 & 0.15 \\
\hline (A9) & $\varepsilon_{t}^{c e x}$ & 2: C, 0 & -1.88 & 0.59 & (A18) & $\varepsilon_{t}^{p l m}$ & 3: C, 1 & -4.26 & $0.02^{* \star}$ \\
\hline (A10) & $\varepsilon_{\mathrm{t}}^{\mathrm{cIm}}$ & 1: C, 0 & -4.12 & $0.00^{* *}$ & (A19) & $\varepsilon_{t}^{b}$ & $4: C, 1$ & -7.16 & $0.00^{* \star}$ \\
\hline (A11) & $\varepsilon_{t}^{\operatorname{lnv}}$ & 4: C, 0 & -5.85 & $0.00^{* *}$ & (A20) & $\varepsilon_{t}^{\text {spr }}$ & $2: C, 1$ & -5.61 & $0.00^{* \star}$ \\
\hline (A12) & $\varepsilon_{t}^{\text {cons }}$ & 3: C, 0 & -4.41 & $0.01^{* *}$ & & & & & \\
\hline
\end{tabular}

$\dagger$ - Includes the number of stochastic trends cointegration is tested for, deterministic trend specification and lag length, ${ }^{* *}$ - indicates rejection of the null hypothesis of a unit root at $5 \%$ and ${ }^{*}$ - rejection at $10 \%$.

Test results confirm cointegration for 8 out of the 13 relationships at 5\% significance level, and for two more relationships at $10 \%$.

Test results for net foreign liabilities, $n f l_{t}(\mathrm{~A} 6)$, export volume, $c_{t}^{e x}(\mathrm{~A} 9)$, and export prices, $p_{t}^{e x}$ (A17) are negative, but cointegration is confirmed when alternative test specification is used by including extra lag or truncating last quarters of the test period (Table A6).

Table A6. Results of Engle-Granger test: alternative specification

\begin{tabular}{|c|c|l|l|c|c|}
\hline Equation & Residual & \multicolumn{1}{|c|}{ Change in model specification } & Test spec $\dagger$ & tstatistics & pvalue \\
\hline$(6)$ & $\varepsilon_{t}^{\text {ntl }}$ & Exclude 2014q2-2014q44 & $2: \mathrm{C}, 1$ & -3.22 & $0.08^{*}$ \\
\hline$(9)$ & $\varepsilon_{t}^{\text {cex }}$ & Exclude 2014q3-2014q4 & $2: \mathrm{C}, 0$ & -3.21 & $0.09^{*}$ \\
\hline$(17)$ & $\varepsilon_{t}^{\text {pex }}$ & Add extra lag & $2: \mathrm{C}, 1$ & -3.33 & $0.07^{*}$ \\
\hline
\end{tabular}

$\dagger$ - Includes the number of stochastic trends cointegration is tested for, deterministic trend specification and lag length, ${ }^{* *}$ - indicates rejection of the null hypothesis of a unit root at $5 \%$ and ${ }^{*}$ - rejection at $10 \%$.

Overall, we conclude that cointegration holds for all the 13 relationships. 


\section{APPENDIX V. ESTIMATED REDUCED FORM MODEL}

As a first step, we estimate dynamic equations in (1) separately as discussed in section III.E. In the final specification statistical tests (correlogram and serial correlation LM test) show no evidence of residual autocorrelation at 5\% significance level. Except for the exchange rate and money stock equations, residuals were found to be homoscedastic (Breusch-PaganGodfrey test). In most cases normality of residuals was not rejected.

Next, we stack equations in a system and estimate it simultaneously using Seemingly Unrelated Regression method:

$$
\begin{aligned}
& \Delta i n v_{t}=-0.53 \varepsilon_{t-1}^{i n v}+0.032+0.45 \Delta\left[p_{t-1}^{i n v}-p_{t-1}^{y}\right]+0.51 \Delta\left[p_{t-2}^{i n v}-p_{t-2}^{y}\right] \\
& \Delta \text { cons }_{t}^{p r}=0.015-0.33 \Delta \text { cons }_{t-1}^{p r}+0.24 \Delta w_{t-1}-0.35 \varepsilon_{t-1}^{c o n s}-0.09 d u m 11 q 2 \_11 q 4_{t} \\
& \text { cons }_{t}^{p u}=0.65 \text { cons }_{t-1}^{p u}+2.17-0.01 d u m 13 q 2 x_{t}-0.01 d u m 11 q 3 x_{t}, \\
& \Delta c_{t}^{e x}=0.019-0.30 \varepsilon_{t-1}^{c e x}-0.25 d u m 08 q 4_{t}+0.07\left(d u m 04 q 4_{t}-d u m 05 q 1_{t}\right) \\
& \Delta c_{t}^{i m}=0.027-0.26 \varepsilon_{t-1}^{c i m}+0.28\left(d u m 04 q 4_{t}-d u m 05 q 1_{t}\right)-0.13\left[d u m 08 q 4_{t}+d u m 09 q 1_{t}\right] \\
& \Delta p_{t}^{i n v}=0.048-0.66 \varepsilon_{t-1}^{p i n v}-0.20 \varepsilon_{t-1}^{i n v}-0.11 \Delta i n v_{t-1} \\
& \Delta p_{t}=-0.006+0.14 d u m 11 q 2_{-} 11 q 4_{t}+0.76 \Delta p_{t-1}-0.13 \Delta s_{t-1}^{u s d}-0.03 \Delta p_{t-1}^{i m_{-} o i l}-0.12 \varepsilon_{t-1}^{q}+0.08 \varepsilon_{t-1}^{y} \\
& +0.96 \Delta p_{t}^{r u s}-0.06 \Delta p_{t-1}^{i n v}-0.04 d u m 14 q 4_{t}+0.07 \Delta c_{t-1}^{e x}-0.07 \Delta w_{t-1} \\
& \Delta p_{t}^{p u}=0.37 \Delta w_{t-1}-0.39 \varepsilon_{t-1}^{p p u}+0.020+0.65 \Delta p_{t-1}-0.23 \Delta p_{t-1}^{p u} \\
& \Delta p_{t}^{e x}=0.66\left[\Delta p_{t}^{r u s_{-} i}+\left(\Delta s_{t}^{r u b}-\Delta s_{t}^{u s d}\right)\right]-0.35 \varepsilon_{t-1}^{p e x}-0.001 \\
& \Delta p_{t}^{\text {im }}=0.35\left[\Delta p_{t}^{\text {rus } i}+\left(\Delta s_{t}^{\text {rub }}-\Delta s_{t}^{u s d}\right)\right]+0.19\left[\Delta p_{t}^{\text {eu }}{ }_{-}+\left(\Delta s_{t}^{\text {eur }}-\Delta s_{t}^{u s d}\right)\right]+0.23 \Delta p_{t-1}^{i m}-0.31 g a p_{-} p_{t-1}^{\text {im }}-0.004 \\
& \Delta s_{t}^{u s d}=1.63 \text { cris }_{t}+0.30 d u m 11 q 2 \_11 q 4_{t}+0.04 d u m 13 q 3 x_{t}-0.008 t \cdot d u m 01 q 1 \_03 q 4{ }_{t}, \\
& \Delta n f l_{t}=0.048-0.23 \varepsilon_{t-1}^{n f l} \\
& \Delta\left[N R_{t}-N R_{t}^{i b}\right]=0.002-0.20 \Delta\left(N R_{t-2}-N R_{t-2}^{i b}\right)-0.56 \varepsilon_{t-1}^{s p r d} \\
& \Delta N R_{t}^{i b}=-0.030-0.38 \text { Inty }_{t-1}+0.19 \text { dum } 11 q 2_{-} 11 q 4_{t}+0.24 \Delta N R_{t-3}^{i b}-0.70 \Delta N R_{t-1} \\
& +0.28 \Delta b_{t-2}-0.29 \Delta p_{t-3}^{i n v}+0.58\left(\Delta_{4} p_{t-1}-\pi_{t-1}^{+}\right)\left[1-d u m 09 q 1_{-} 09 q 4_{t}-d u m 11 q 2_{-} 12 q 3_{t}\right]
\end{aligned}
$$




$$
\begin{aligned}
& \Delta w_{t}=0.10 \varepsilon_{t-1}^{q}+0.008+0.55 \Delta p_{t-1}-0.38 \Delta p_{t-3}+0.23 \Delta w_{t-1}+0.46 \Delta w_{t-2}+0.17 \Delta c_{t-1}^{e x}+0.11 \Delta c_{t-2}^{e x} \\
& \Delta m_{t}=0.54 \Delta m_{t-1}+0.041-0.33\left[\varepsilon_{t-1}^{v}+\varepsilon_{t-1}^{y g a p}\right] \\
& \Delta b_{t}=0.32 \Delta b_{t-1}+0.057+0.60 \varepsilon_{t-1}^{b}+0.32 \Delta r e q_{t}+0.22 \operatorname{Inty} y_{t}-0.20\left[\varepsilon_{t-1}^{v}+\varepsilon_{t-1}^{y g a p}\right] \\
& \operatorname{inv} v_{t}^{\text {Gov }}=-1.75+0.030 t+1.37 \text { dum } 11 q 2 x_{t}-0.041 t \cdot d u m 11 q 2 x_{t}+0.55 \operatorname{inv} v_{t-i}^{\text {Gov }}
\end{aligned}
$$

According to estimated relationship (A32), during the currency crises the size of devaluation of the nominal BYR/USD exchange rate was proportional to real exchange rate misalignment with the coefficient 1.63. Komkov et al. (2008) estimate the full share of import costs (direct and indirect) in the consumption basket in Belarus at 0.39. Then, nominal devaluation of $1.63 \%$ would produce the $1^{\text {st }}$ round effect on inflation equal $0.64 \%$ and corresponds to $1 \%$ real devaluation. Therefore, if all other costs are fixed, this nominal devaluation in this proportion to the misalignment is just enough to ensure real exchange rate adjustment.

According to (A37), money supply $\left(m_{t}\right)$ is determined by demand for money captured by the money velocity gap $\left(\varepsilon_{t}{ }^{\nu}\right)$ plus the output gap $\left(\varepsilon_{t}^{\text {ygap }}\right)$, which is consistent with p-star model. Thus, money stock adjusts to real money demand deviation from its long-term trend captured by velocity trend and potential (rather than actual) output level.

Price $\left(p_{t}\right)$ and wage $\left(w_{t}\right)$ dynamics is persistent and reacts slowly to the real exchange rate misalignment $\left(\varepsilon_{t}^{q}\right)$. So, given the rigid nominal exchange rate, the deviations of real exchange rate from equilibrium are likely to be persistent as well. Inflation reacts to output gap $\left(\varepsilon_{t}^{y}\right)$, but not to the money velocity gap $\left(\varepsilon_{t}^{v}\right)$, so there are no inflationary pressures stemming from money demand deviations. Within this setting, wages would be positively reacting to output fluctuations as captured in (9), while inflation would rather be reacting to potential output, as disinflationary pressure from short-run productivity gains in (9) would be just compensated with inflationary pressure from output gap (8). 


\section{APPENDIX VI. IMPUlSE RESPONSES TO DEMAND, INFLATION AND MONETARY BASE SHOCKS}

\section{A. Monetary Base Shock}

The effect of 1 percent monetary base shock on the economy is negligible with no effect on output or prices. This confirms our earlier finding that monetary base was driven endogenously by demand for liquidity, rather than used as an active policy instrument (Figure A1).

There is some small and short-lived effect in the financial market, however. Monetary expansion is associated with limited capital outflow, which could be due to credit currency substitution as more credits can be provided in domestic currency and, hence, less foreign financing is needed. Policy rate reacts with immediate tightening, which brings liquidity down and reverts foreign financing, so that the equilibrium is largely restored within a year.

Figure A1. Impulse response to 1 percent monetary base shock
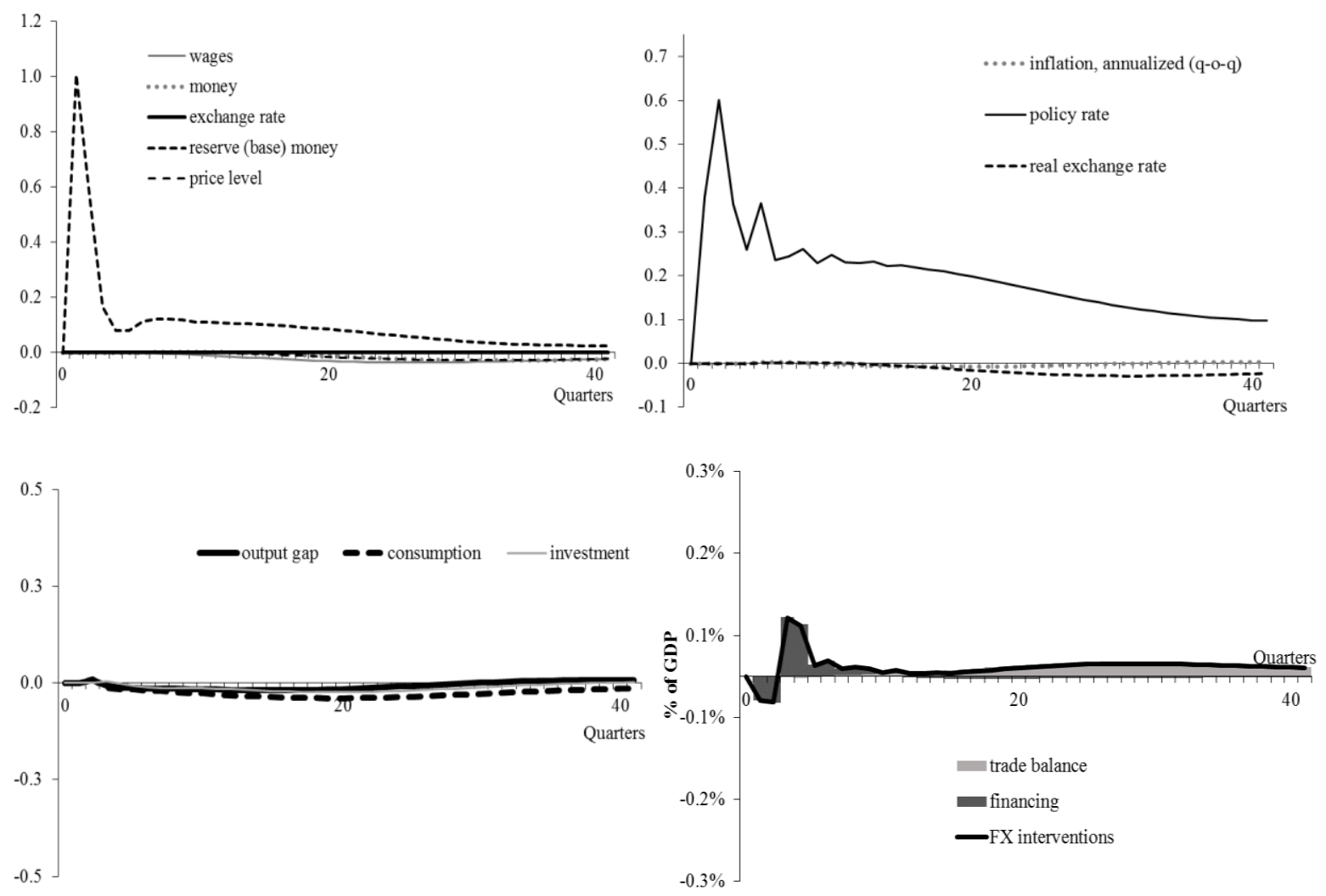


\section{B. Domestic Demand Shock}

The effect of 1 percentage point domestic demand shock on the economy is limited in scope and short-lived in time (Figure A2). Increase in demand is satisfied with supply of domestic goods and imports. Thus, output increases by 0.6 percent within one quarter, whereas foreign trade balance deteriorates by 0.4 percent of GDP. In response, the NBRB lets the money market rate to increase to defend the peg, although the scope of the reaction is too small to prevent the loss of foreign reserves.

Wages and prices almost do not react and the demand shock fades quickly, so the economy largely returns to the equilibrium in two years. The output gap is closed by the second quarter, while it takes one more year to eliminate the trade deficit.

Figure A2. Impulse response domestic demand shock (1 percent investment shock)
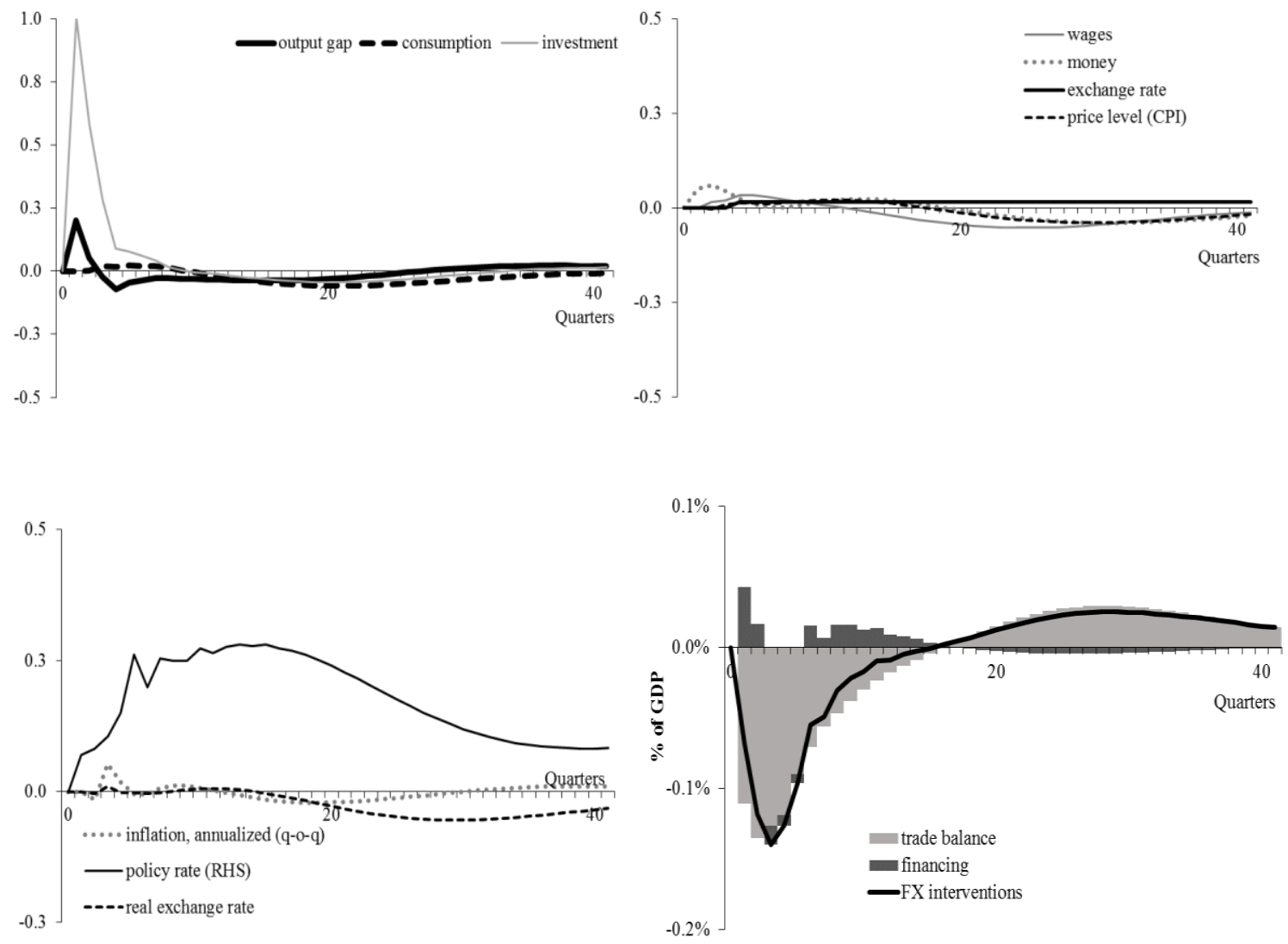


\section{Inflation Shock}

Unlike the demand shock, the inflation shock of 1 percent has a significant impact on economy (Figure A3).

Increase in price level is accompanied by negative output gap. The recession is partly due to a fall of domestic demand, but mostly is driven by a substitution effect, as immediate real exchange rate appreciation shifts demand towards foreign goods with ensuing foreign trade balance deterioration.

In response to inflationary pressures and losses of foreign reserves, the NBRB lets the money market rate to increase, albeit with some delay: after an immediate decline interest rates increase by 4 percentage points.

Higher interest rate is not enough to offset pressures on the FX reserves: the NBRB intervenes for about $2 \frac{1}{2}$ years (net sell of foreign assets worth 1.9 percent GDP) to defend the exchange rate peg. Money supply is tightened as well, implying money stock decline in real terms. Loss of price competitiveness combined with tighter money induces a prolonged recession with the output gap hitting negative 1.5 percent at its trough. This also puts pressure on real wages.

Eventually, all these developments - the negative output gap, decline in real wages and tighter money - make inflationary pressures to reverse by the end of the first year. Prices gradually converge to their long-run level anchored by the nominal exchange rate. The economy largely returns to equilibrium within five years.

Figure A3. Impulse response to 1 percent inflation shock
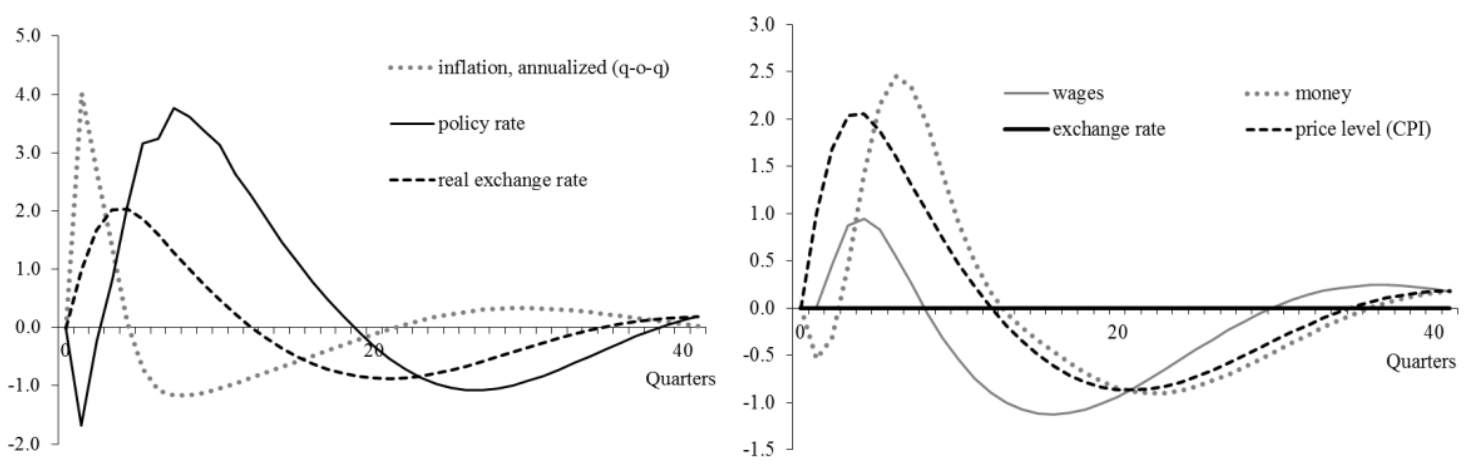


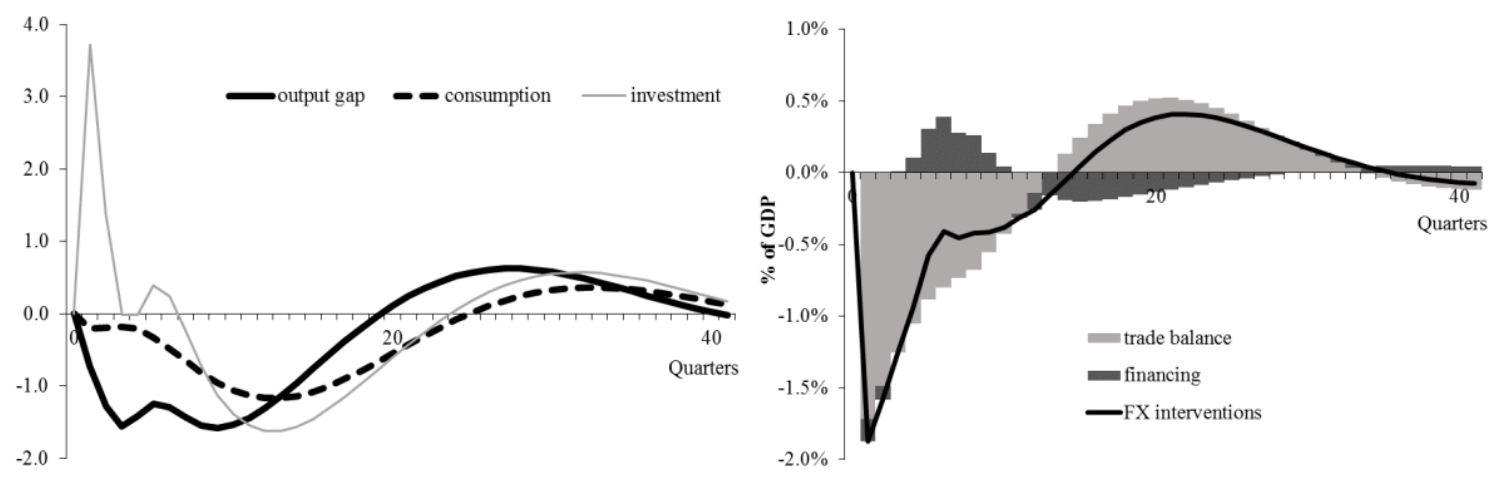

